Open Access

\title{
A novel anti-inflammatory natural product from Sphaeranthus indicus inhibits expression of VCAM1 and ICAM1, and slows atherosclerosis progression independent of lipid changes
}

\author{
Rai Ajit K. Srivastava ${ }^{1,2^{*}}$, Sapna Mistry ${ }^{1,3}$ and Somesh Sharma ${ }^{1}$
}

\begin{abstract}
A large body of evidence suggests that atherosclerosis is an inflammatory disease, in which cytokines and growth factors play a major role in disease progression. The methanolic extracts of Sphaeranthus indicus as well as its active ingredient, 7-hydroxy frullanoide (7-HF), are shown to suppress LPS-induced cytokine production from mononuclear cells, and inhibit the expression of VCAM1, ICAM1 and E-selectin by TNF-a- stimulated HUVECs in a concentration-dependent manner. We tested the hypothesis that the inhibition of cytokines and adhesion molecules should attenuate the progression of atherosclerosis, independent of changes in the lipid profile. Studies were carried out in two animal models: a high fat-fed $L D L r^{-1-}$ mouse and a high fat-fed hyperlipidemic hamster. Methanolic extract of S. indicus was dosed to hyperlipidemic $\mathrm{LDLr}^{-/-}$at 100 and $300 \mathrm{mg}$ (equivalent to 20 and $60 \mathrm{mg}$ 7-HF)/kg body weight/ day for 8 weeks, and plasma lipids as well as aortic lesion area were quantitated. Hyperlipidemic hamsters were treated with one dose of $200 \mathrm{mg} / \mathrm{kg} /$ day. S. indicus extract treatment did not alter the lipid profile in both animal models, but reduced aortic lesion area in LDLr ${ }^{-1-}$ mice and hyperlipidemic hamsters by $22 \%$ and $45 \%$, respectively. Fenofibrate, included as a reference agent, decreased aortic lesions by $26 \%$ in $\mathrm{LDLr}^{-1-}$ mice and $84 \%$ in hyperlipidemic hamsters, respectively, which was driven by massive reductions in proatherogenic lipoproteins. The lipid-independent anti-atherosclerotic activity of $S$. indicus was associated with the reductions in the circulating levels of MCP-1, TNF-a, and IL-6 via phosphorylation and degradation of IkB-a that prevents translocation of NF-kB in the nucleus to induce proinflammatory cytokines. Our findings demonstrate that anti-inflammatory agents that lower pro-inflammatory proteins inhibit the progression of atherosclerosis. The methanolic extract of S. inducus, currently being used to treat psoriasis, offer promise to benefit individuals who have high circulating pro-inflammatory cytokines, and predisposed to coronary artery disease.
\end{abstract}

\section{Introduction}

A number of studies for the past 15 years suggest that atherosclerosis, the main cause of coronary artery disease $(C A D)$, is an inflammatory disease in which inflammation plays a key role in setting the stage as well as causing the progression of atherosclerosis (Reviewed in [1-4]. Immune cells are predominantly present in the early atherosclerotic lesions, and their effector molecules

\footnotetext{
* Correspondence: ajitsriva@gmail.com

'Department of Pharmacology, Piramal Life Sciences Ltd, Mumbai, India

${ }^{2}$ Present address: Integrated Pharma Solutions, Philadelphia, Department of Pharmacology \& Physiology, Drexel University School of Medicine, Philadelphia, USA

Full list of author information is available at the end of the article
}

have been shown to accelerate progression of the lesions leading to acute coronary syndrome $[3,5]$. Thus, immune mechanisms interact with metabolic risk factors to initiate, propagate, and activate lesions in the arteries. In addition to vascular endothelial and smooth muscle cells, blood borne inflammatory and immune cells constitute an important part of an atheroma, which is preceded by an accumulation of lipid-laden cells in the subendothelium [3, 6-9]. Endothelial cells recruit leukocytes by selectively expressing major adhesion molecule on the surface. Examples of specific adhesion molecules involved in initiation of atherosclerotic plaques include vascular cell adhesion molecule-1 
(VCAM-1), intercellular adhesion molecule (ICAM1), and endothelial cell selectin (E-selectin) $[8,9]$. The chemoattractant cytokine, monocyte chemoattractant protein-1 (MCP-1), interacts with the monocyte chemokine receptor CCR2, recruiting the monocytes to the arterial endothelium and facilitating their entry in the subendothelial space $[9,10]$.

During the past one decade, inflammatory nature of atherosclerosis has attracted basic, translational, and clinical researchers to find scientific basis leading to a robust link between inflammatory biomarkers and cardiovascular disease (CVD) in outcome studies. Towards this end, high sensitivity c-reactive protein (hsCRP), an acute phase reactant released during inflammatory processes $[11,12]$, has been recognized as a powerful predictor of traditional markers of cardiovascular risk [13-15]. Basic and clinical research data suggest that treatment with statins (3-hydroxy-3-methylglutaryl coenzyme A reductase inhibitors) to lower low-density lipoprotein (LDL) cholesterol levels also reduces hsCRP [16]. Additional support for the anti-inflammatory and immunimodulatory actions of statins came from clinical research. Thus, the magnitude of risk reduction associated with statin therapy may exceed that expected on the basis of the LDL-C lowering alone. Prospective evidence provided by the JUPITER trial (Justification for the Use of Statins in Primary Prevention: an Intervention Trial Evaluating Rosuvastatin) demonstrated that patients with normal LDL-C levels but elevated hsCRP levels showed highly significant $(-44 \%)$ reduction in adverse cardiovascular events [17], suggesting additional benefit of hsCRP reduction and demonstrating an inflammatory component in the CVD risk.

Immune-mediated inflammatory disease, including atherosclerosis, psoriatric arthritis (PsA) [18-21], and rheumatoid arthritis (RA) [22-26], are characterized by common inflammatory morbidity and mortality. Chronic activation of innate and adaptive inflammatory pathways that provide an essential defense against "foreign" substances ranging from bacterial products to endogenous oxidized lipids, may contribute to atherosclerotic plaque progression, destabilization, and ultimately rupture with subsequent clinical sequelae such as myocardial infarction or stroke [20, 27].

Recently, it was demonstrated that the extract of Sphaeranthus indicus as well as its active ingredient, 7HF, a sesquiterpene lactone, inhibits the LPS-induced release/synthesis of several pro-inflammatory mediators such as TNF- $\alpha$, IL- $1 \beta$ and IL- 6 in freshly isolated human peripheral blood monocytes [28]. Moreover, both of these prevented constitutive proinflammatory cytokine production in primary cultures of rheumatoid synovial cells, and oral administration of 7-HF effectively suppressed the clinical signs of established arthritis in
DBA/1 collagen-induced arthritis model [29]. However, the antiatherosclerotic activities of S. indicus extract and 7-HF have not been evaluated. We hypothesized that the anti-inflammatory activities of S. indicus extract and 7-HF, shown to cause lowering of VCAM1, ICAM1, and Eselectin, may inhibit the progression of arterial lesion formation. To test this hypothesis, we employed two widely studied animal models, LDLr ${ }^{-/-}$[30] and hyperlipidemic hamsters [31], and evaluated antiatherosclerotic activities of $S$. indicus extract. Our results show that the antiatherosclerotic efficacy of $S$. indicus methanolic extract occurs via attenuation of proinflammatory cytokines and adhesion molecules, and is independent of changes in the plasma lipid profiles.

\section{Materials and methods Reagents}

RPMI 1640 medium, anti- $\beta$-actin, anti-histone, phenazine methosulfate (PMS), Dulbecco's phosphate buffered saline (DPBS) and fetal bovine serum (FBS) were purchased from Sigma. Calpain Inhibitor I, and antibodies against IкB $\alpha$ phosphorylated ІкB $\alpha$ p 65 were obtained from Calbiochem (Merck Biosciences). AntiICAM-1 (clone BBIG-I1) anti-VCAM-1 (clone BBIG-V1) and anti-E-selectin (clone BBIG-E4), isotype control mouse $\operatorname{IgG}_{1}$ (clone 11711.11), the secondary antibody (anti-mouse IgG-HRP antibody) and bacteria derived recombinant human TNF- $\alpha$ were products of $R \& D$ Systems (Minneapolis, MN). Protease inhibitor cocktail was procured from Roche. The CellTiter $96^{\circ}$ Aqueous One Solution Cell Proliferation Assay were purchased from Promega (Madison, WI).

Source of Sphaeranthus Indicus and 7-hydroxy frullanolide Methanolic extract of the fruits of Sphaeranthus Indicus was prepared in-house and dissolved in DMSO as a $20 \mathrm{mg} / \mathrm{ml}$ stock as described [28]. 7-hydroxy frullanolide $(7 \mathrm{HF})$, isolated in-house from the above plant was dissolved in DMSO as a $20 \mathrm{mM}$ stock. It was purified and identified with the use of ESI-MS and ${ }^{1} \mathrm{H}$ - and ${ }^{13}$ C-NMR analyses [28].

\section{Human peripheral blood mononuclear cells assay}

Human peripheral blood mononuclear cells (PBMC) were harvested using Ficoll- Hypaque density gradient centrifugation (1.077 g/ml; Sigma Aldrich; St. Louis, MO) from healthy volunteers and suspended in assay medium [RPMI 1640 culture medium (Sigma Aldrich) containing $10 \%$ heat inactivated fetal bovine serum (FBS; JRH Biosciences; Lenexa, KA), 100U/ml penicillin (Sigma Aldrich) and $100 \mu \mathrm{g} / \mathrm{ml}$ streptomycin (Sigma Aldrich)]. PBMC $\left(2 \times 10^{5}\right)$ per well were transferred into a 96-well plate. The cells were pre-treated with varying concentrations of $7 \mathrm{HF}, S$. indicus extract, or $0.5 \%$ dimethyl sulfoxide (DMSO) or 
$10 \mu \mathrm{M}$ 4- (4-fluorophenyl)-2-(4-methylsulfinylphenyl)5-(4-pyridyl) imidazole [SB203580; a p38 MAPK inhibitor which is known to suppress induced production of TNF- $\alpha$ and IL-6; Sigma Aldrich] for $1 \mathrm{~h}$ at $37{ }^{\circ} \mathrm{C}, 5 \%$ $\mathrm{CO}_{2}$ and stimulated with $1 \mu \mathrm{g} / \mathrm{ml}$ lipopolysaccharide (LPS; Escherichia coli serotype 0127:B8; Sigma Aldrich). The cells were incubated for $6 \mathrm{~h}$ at $37{ }^{\circ} \mathrm{C}, 5 \% \mathrm{CO}_{2}$ followed with collection of supernatants and assayed for TNF- $\alpha$, IL-6, IL-8, and IL-1 $\beta$ by Enzyme-Linked Immunosorbent Assay (ELISA; OptiEIA ELISA sets; BD Biosciences). The $50 \%$ inhibitory concentration $\left(\mathrm{IC}_{50}\right)$ values were calculated by a nonlinear regression method using GraphPad software (Prism 3.03). In all experiments, a parallel plate was run to ascertain the toxicity of 7HF. The toxicity was determined using the CellTiter 96 ${ }^{\circ} \mathrm{AQ}_{\text {ueous }}$ One Solution Cell Proliferation Assay (Promega; Madison, WI). In every experiment, each condition was run in triplicate wells.

\section{Endothelial cell culture}

Human umbilical vein endothelial cells (HUVECs) and the complete medium were obtained from Cascade Biologics (Portland, Oregon). Cells were grown in endothelial cell growth medium M200 supplemented with $2 \%$ low serum growth supplements as per the manufacturer's recommended protocol. The growth medium was changed every other day until confluence. Cells under passage 8 were used for this study. The cells used for the experiments had a viability $>98 \%$ as determined by trypan blue exclusion test.

\section{Evaluation for the viability of endothelial cells}

The CellTiter $96^{\circ}$ Aqueous One Solution Cell Proliferation Assay (Promega) was used to assess cell viability. The assay is composed of the tetrazolium compound MTS (3-(4,5-dimethylthiazol-2-yl)-5-(3-carboxymethoxyphenyl)-2-(4-sulfophenyl)-2H-tetrazolium, inner salt) and an electron coupling reagent (PMS). The soluble product in the medium was measured with a spectrophotometer at 490-nm absorbance. Background absorbance from the control wells (same media, no cells) was subtracted. Cells incubated in control media were considered $100 \%$ viable.

\section{Cell enzyme-linked immunosorbent assay}

The surface expression of endothelial cell adhesion molecules was quantified using cell enzyme-linked immunosorbent assay. Briefly, confluent HUVECs in 96well fibronectin-coated plates were pretreated with various concentrations of $S$. indicus or 7-HF for $30 \mathrm{~min}$ before being stimulated with $1 \mathrm{ng} / \mathrm{mL}$ TNF- $\alpha$ for the indicated time. The expressions of ICAM-1 and Eselectin were evaluated after TNF- $\alpha$ stimulation for $4 \mathrm{~h}$, and expression of VCAM-1 was evaluated after $6 \mathrm{~h}$ of stimulation. The cells were fixed with $1 \%$ paraformaldehyde and the non-specific binding of antibody was blocked using bovine serum albumin (2\% in DPBS). The cells were then washed and incubated with monoclonal mouse anti-human ICAM-1, VCAM-1, E-selectin or the isotype control mouse IgG1 overnight at $4{ }^{\circ} \mathrm{C}$. Subsequently, cells were washed and incubated with a horseradish peroxidase-conjugated goat anti-mouse IgG for $90 \mathrm{~min}$. Binding of the secondary antibody was determined by incubating with $3,3^{\prime}, 5,5^{\prime}$ tetramethylbenzidine (TMB) substrate from BD Biosciences (SD California) and then terminating the reaction by $2 \mathrm{~N}$ sulphuric acid. Surface expression of adhesion molecules was quantified by measuring absorbance at $490 \mathrm{~nm}$ in an automated microtitre plate reader (Spectramax, Molecular Devices, USA).

\section{IkBa phosphorylation}

To assay I $\mathrm{K} \mathrm{B} \alpha$, cytoplasmic extracts were prepared from cells pretreated with either $S$. indicus extract or $7 \mathrm{HF}$ for $2 \mathrm{~h}$ and then stimulated with TNF- $\alpha$ either in the presence or absence of ALLN, a calpain inhibitor, resolved on $10 \%$ sodium dodecyl sulfate-polyacrylamide gels. After electrophoresis, the proteins were transferred to nitrocellulose membrane, probed with antibodies against either ІкB $\alpha$ or phosphorylated IкB $\alpha$ at serine 32 , and detected by chemiluminescence (ECL; Sigma).

\section{NF-KB protein localization}

For the determination of NF-kB localization, Western blot analysis was carried out with cytoplasmic and nuclear extracts using anti-human NF- $\mathrm{kB}$ primary antibody. These extracts were prepared as per manufacturers protocol (Chemicon). Briefly, treated cells were lysed in $300 \mu \mathrm{l}$ of hypotonic lysis buffer containing $10 \mathrm{mM}$ HEPES (pH 7.9), $1.5 \mathrm{mM} \mathrm{MgCl}_{2}, 10 \mathrm{mM} \mathrm{KCl}$, 0.5-5 mM DTT, $0.1 \%$ Triton X-100, sodium orthovanadate, $1 \mathrm{mM}$ and protease inhibitor cocktail. The residual pellet after cytosolic fraction collection was treated with extraction buffer containing $20 \mathrm{mM}$ HEPES (pH7.9), $1.5 \mathrm{mM} \mathrm{MgCl}_{2}, 0.42 \mathrm{M} \mathrm{NaCl}, 0.2 \mathrm{mM}$ EDTA, $0.5-5 \mathrm{mM}$ DTT, $1.0 \%$ NP-40, $25 \%$ (v/v) glycerol, sodium orthovanadate, $1 \mathrm{mM}$, and protease inhibitor cocktail. Twenty microgram protein were taken for Western Blot analysis as described above.

\section{In vivo cytokine production study}

Group of 10 mice were treated orally with Sphaeranthus Indicus methanolic extract, $60 \mathrm{~min}$ prior to lipopolysaccharide injection $(1 \mathrm{mg} / \mathrm{kg}$, i.p.). Levels of TNF- $\alpha$ in the plasma, were measured $1.5 \mathrm{~h}$ after lipopolysacchride injection, and IL-1 $\beta$ were done $4 \mathrm{~b}$ after LPS treatment. 


\section{Real-time quantitative PCR analysis}

Quantitation of messenger RNA (mRNA) was done in aortic total RNA by real-time quantitative RT-PCR using an ABI Prism 7700 sequence detector. All PCR reactions were performed in a total volume of $50 \mu \mathrm{l}$ and included the following components: cDNA derived from $20 \mathrm{ng}$ of total RNA, $400 \mathrm{nM}$ each of forward and reverse primers, RNase-free water, and $25 \mu \mathrm{l}$ of Power SYBR Green PCR Master Mix (ABI), an optimized buffer system containing AmpliTaq Gold DNA polymerase and dNTPs. All PCR reactions were performed in quadruplicate using pooled cDNA samples $(n=6)$. Cycling parameters were as follows: after an initial denaturation step for $10 \mathrm{~min}$ at $95{ }^{\circ} \mathrm{C}, 40$ subsequent cycles were performed in which samples were denatured for $15 \mathrm{~s}$ at $95{ }^{\circ} \mathrm{C}$ followed by primer annealing and elongation at $60{ }^{\circ} \mathrm{C}$ for $1 \mathrm{~min}$. Relative quantities of mRNA were calculated from $\mathrm{C}_{\mathrm{T}}$ values using the comparative $C_{T}$ method $\left(\Delta \Delta C_{T}\right.$; [32] using GAPDH as an internal reference. Primer pairs for real-time PCR were designed using Primer3 software and sequence information obtained from GenBank (NCBI).

\section{Atherosclerosis intervention study in hamsters Animals and diet}

All animal procedures were performed as per guidelines provided by the Institutional Animal Care and Use Committee. Golden Syrian (GS) hamsters (10-12 weeks old) obtained from Charles River, were housed in groups of three in appropriately sized solid-bottom cages with contact bedding. Room lighting conditions were adjusted to $12 \mathrm{~h}$ light and $12 \mathrm{~h}$ dark cycle as follows: light between the hours of $6 \mathrm{AM}$ to $6 \mathrm{PM}$ and dark between the hours of $6 \mathrm{PM}$ to $6 \mathrm{AM}$. All animals were allowed to acclimate for 5 days in the vivarium and were fed standard rodent chow unless otherwise mentioned before initiating the study.

\section{Study details}

After the acclimation period, baseline blood chemistry was done in animals after 12-h fasting followed by blood $(700 \mu \mathrm{l}-800 \mu \mathrm{l})$ withdrawal by retro-orbital puncture in a $3 \mathrm{ml}$ Vacutainer tube containing $\mathrm{K}_{3}$ EDTA. Blood samples were centrifuged $\left(4000 \mathrm{rpm}, 20 \mathrm{~min}, 4{ }^{\circ} \mathrm{C}\right)$ in an Eppendorf tube to obtain plasma, which was transferred $(250-300 \mu \mathrm{l})$ into a clean tube. The aliquot of plasma sample was analyzed for triglycerides, total cholesterol, LDL-C, direct-HDL-C, glucose, AST and ALT. LDL, triglycerides, cholesterol, and glucose were quantitated on automated chemistry analyzer, Hitachi 917, using Roche diagnostic kits (Indianapolis). After bleeding, animals were earmarked for identification and then were returned to their cages and feed replaced. All animals were put on a high fat diet consisting of Purina 5001 plus $10 \%$ coconut oil, $10 \%$ corn oil, $0.5 \%$ cholesterol, and $5 \%$ fructose. This diet composition accelerates hyperlipidemia in hamsters. Animals were fed high fat diet for 4 weeks. This study started with a total of 50 animals. At the end of 4 weeks of feeding high fat high cholesterol diet, the hamsters were fasted overnight and bled as described above. Plasma samples were analyzed for total cholesterol, triglycerides, LDL-C, HDL-C, glucose, AST and ALT as described above. Based on the body weight, and blood chemistry those animals that did not develop adequate hyperlipidemia (total cholesterol $>1000 \mathrm{mg} / \mathrm{dl}$ and total triglycerides $>1200 \mathrm{mg} / \mathrm{dl}$ ) were excluded from the study before grouping [33]. Animals were then randomly grouped into 3 groups of 10 animals in each group as follows: group 1- vehicle control CMC $0.5 \%$; group 2- fenofibrate $100 \mathrm{mg} / \mathrm{kg} /$ day; group 3- methanolic extract of S. indicus $200 \mathrm{mg} / \mathrm{kg} /$ day. Animals were fed high fat high cholesterol diet and concomitantly dosed by oral gavage once daily in the morning between 8 and 9 AM. At the end of 10 weeks of treatment, hamsters were euthanized under $\mathrm{CO}_{2}$ and blood withdrawn by cardiac puncture and processed as described above. The thorax was opened and vasculature perfused first with heparinized saline $(40$ units $/ \mathrm{ml})$ for 2 min and then with $10 \%$ formalin for $5 \mathrm{~min}$. The aorta attached to heart and containing aortic arch, thoracic and abdominal aorta to the femoral artery bifurcation were removed and placed in $10 \%$ formalin for en face staining and lesion quantitation. Aortic lipid contents were quantitated by en face staining with Oil Red $\mathrm{O}$ and atherosclerotic lesion area coverage determined by image analysis.

Isolated aortae from the above study were placed on to a tray containing black wax. Connective tissues sticking around the artery were removed as much as possible. Abdominal aorta and renal arteries, iliac bifurcation, aortic arch and major branches were exposed. The aorta was snipped at the heart where it leaves the heart. Major branches were snipped at approximately $0.5 \mathrm{~cm}$ away from where it joins the aorta. Iliac arteries were snipped from the bifurcation point. The aorta was placed into $10 \%$ formalin for lesion measurement.

Each section of the aorta was opened longitudinally and pinned to a black wax plate using stainless steel pins. The plate containing the aorta sections was then rinsed with $70 \%$ ethanol (5 min), immersed in Oil Red $\mathrm{O}$ staining solution $(10 \mathrm{~min})$ followed by destaining with $70 \%$ ethanol on a shaker for $5 \mathrm{~min}$ at room temperature. The aorta was rinsed with deionized water and then submerged with PBS. Quantitation and imaging was done as described [33]. Atherosclerosis burden was expressed as \% lesion per area. 


\section{Atherosclerosis intervention study in $\mathrm{LDLr}^{-/-}$mice Animals and diet}

Male $\mathrm{LDLr}^{-1-}$ mice (C57Bl/6 J background) were procured from Jackson Laboratories (Bar Harbor, Maine) at 6 weeks of age. Mice were allowed to acclimatize on regular chow diet for one week followed by feeding a high fat high cholesterol (HF) diet with $45 \%$ calories from butter fat plus $0.21 \%$ cholesterol for 2 weeks to acclimatize to the high fat diet. On an average, the food consumption was around $3 \mathrm{~g} /$ day. One group of mice was fed rodent chow, Purina $5001(n=11)$.

\section{Study details}

After the acclimation period of one week, baseline blood chemistry was done in animals after 4-h fasting followed by blood $(150 \mu \mathrm{l})$ withdrawal by retro-orbital puncture tube containing $\mathrm{K}_{3}$ EDTA. Each blood sample was centrifuged (4000 rpm, $20 \mathrm{~min}, 4{ }^{\circ} \mathrm{C}$ ) using an Eppendorf tube, and the supernatant transferred into a new clean tube. The aliquot of plasma sample was analyzed for triglycerides and total cholesterol. After bleeding, animals were earmarked for identification and then were returned to their cages and feed replaced. All animals were put on a high fat diet consisting of Purina 5001 plus $21 \%$ fat, and $0.21 \%$ cholesterol.

The LDLr ${ }^{-/}$mice on high fat diet were divided into 3 groups ( $n=11$ /group) as follows: Group 1 - Vehicle, high fat high cholesterol (HF) with $45 \%$ calorie from butter milk and $0.21 \%$ cholesterol; Group 2, HF diet plus Methanolic extract of $S$. indicus $(100 \mathrm{mg} / \mathrm{kg}$ body weight/day); Group 3, HF diet plus methanolic extract of S. indicus $(300 \mathrm{mg} / \mathrm{kg}$ body weight/day). Mice were fed pelleted HF diet, and test agent was administered by oral gavage in the morning once daily. New batches of dosing solution was prepared every week and stored as aliquots at $4{ }^{\circ} \mathrm{C}$. Food was replaced with fresh food at the intervals of every 3 days. Body weights were monitored every week, and feeding continued for 8 weeks. At the end of 8 weeks of treatment, mice were bled retro-orbitally under isoflurane anesthesia, and plasma analyzed for triglycerides, cholesterol, LDL-C, HDL-C, glucose, and cytokine level. Mice were sacrificed by carbon dioxide asphyxiation. Aorta were removed, and processed for Oil Red O staining as described [34, 35]. Aortae from 4 mice in each group were isolated without formalin fixing to prepare total RNA [30].

\section{Statistical analysis}

Mean values of treated groups were compared to those of the vehicle treated group. Statistical significance was determined by ANOVA. Statistical comparisons across treatment groups were done. All results were presented as mean \pm SD. A p value of $<0.05$ was considered significant.

\section{Results}

\section{S. indicus extract decreases TNF-a stimulated} pro-inflammatory cytokines in human peripheral blood monocytic cells

Screening of natural products for their anti-inflammatory activities were performed in monocytes isolated from human peripheral blood. To induce cytokine production, PBMC was stimulated with LPS and inhibition of cytokine secretion was measured. As shown in Fig. 1, S. indicus extract inhibited pro-inflammatory cytokines, TNF- $\alpha$, IL1- $\beta$, IL-6, and IL-8. The concentration needed to achieve maximal inhibition for each cytokines was found to be different. Whereas significant inhibition in the secretion of IL1- $\beta$ was seen at as low as $1 \mu \mathrm{g} / \mathrm{ml}$ concentration, it required 3 and $10 \mu \mathrm{g} / \mathrm{ml}$ S. indicus extract to have similar inhibition for TNF- $\alpha$ and IL-6 production. While $30 \mu \mathrm{g} / \mathrm{ml} \mathrm{S}$. indicus extract resulted in $>80 \%$ inhibition in TNF- $\alpha$, IL1- $\beta$ and IL- 6 production, inhibition of IL- 8 secretion was $\sim 70 \%$. The $\mathrm{IC}_{50}$ for TNF- $\alpha$, IL1- $\beta$, IL-6, and IL- 8 were $3.5,2.1,10$, and $25 \mu \mathrm{g} / \mathrm{ml}$, respectively. The maximal efficacious concentration showed no toxicity in this study.

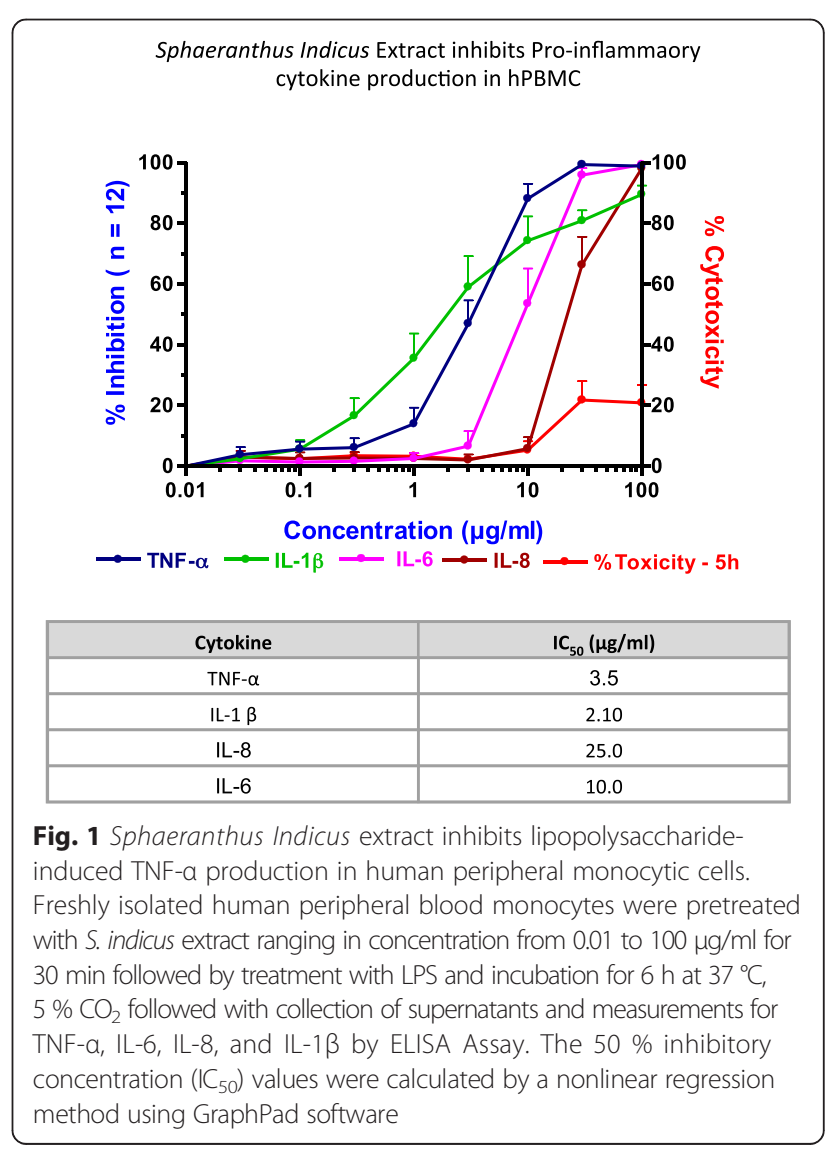




\section{S. indicus extract and 7-HF decrease the expression of VCAM-1, ICAM-1 and E-selectin by TNF-a stimulated HUVECs}

As cell adhesion molecules play an important role during inflammation, we analysed the effect of different concentrations of S. indicus extract and 7-HF on TNF$\alpha$-induced cell surface expression of these molecules. In accordance with previous studies, ICAM-1 and ESelectin were expressed at low levels in unstimulated HUVECs, but their expression was increased after TNF- $\alpha$ stimulation (data not shown). High-dosage $(10 \mu \mathrm{g} / \mathrm{ml})$ but not low-dosage $(3 \mu \mathrm{g} / \mathrm{ml})$ S. indicus extract significantly inhibited TNF- $\alpha$ induced ICAM-1 $(54 \pm 14 \%)$, VCAM-1 (64 $\pm 9 \%)$ and E-selectin (88 \pm $8 \%$ ), respectively (Fig. 2). The $\mathrm{IC}_{50}$ values of $S$. indicus extract to ICAM-1, VCAM-1 and E-selectin expressio were $11.43,6.43$, and $4.61 \mu \mathrm{g} / \mathrm{ml}$, respectively. $7-\mathrm{HF}$, at a concentration of 1 and $3 \mu \mathrm{M}$ also significantly reduced the expression of ICAM-1 (52 $\pm 16 \%$ and $75 \pm$ $17 \%)$, VCAM-1 (76 $\pm 3 \%$ and $90 \pm 7 \%)$ and E-selectin $(96 \pm 2 \%$ and $100 \pm 0 \%)$ respectively. The $\mathrm{IC}_{50}$ values of 7-HF to ICAM-1, VCAM-1 and E-selectin were 0.73,
0.39 , and $0.29 \mu \mathrm{M}$, respectively. Taken together, these findings indicate that $S$. indicus extract as well as its active ingredient, 7-HF specifically inhibit cytokineinduced expression of adhesion molecules in a dosedependent manner.

The cell cytotoxicity was assessed by MTS assay. Treatment of HUVECs with $1 \mathrm{ng} / \mathrm{mL}$ of TNF- $\alpha$ did not result in cytotoxicity (data not shown). When incubated with 1,3 and $10 \mu \mathrm{g} / \mathrm{mL}$ of $S$. indicus extract, cell viability was $89 \pm 3 \%, 89 \pm 3 \%$ and $100 \pm 0 \%$ respectively. Treatment with $0.3,1$ and $3 \mu \mathrm{M}$ did not affect cell viability $(89 \pm 3 \%, 89 \pm 3 \%$ and $100 \pm 0 \%$ respectively).

\section{Effect of S. indicus extract on inhibition of TNF-a and IL-1 $\beta$ production in mice}

Groups of 10 mice were treated orally with Sphaeranthus Indicus methanolic extract, $60 \mathrm{~min}$ prior to lipopolysaccharide injection ( $1 \mathrm{mg} / \mathrm{kg}$, i.p.). Levels of TNF- $\alpha$ in the plasma were measured $1.5 \mathrm{~h}$ after lipopolysaccharide injection, and IL-1 $\beta$ were done $4 \mathrm{~h}$ after LPS treatment. The results shown in Fig. 3a suggest a dose-dependent

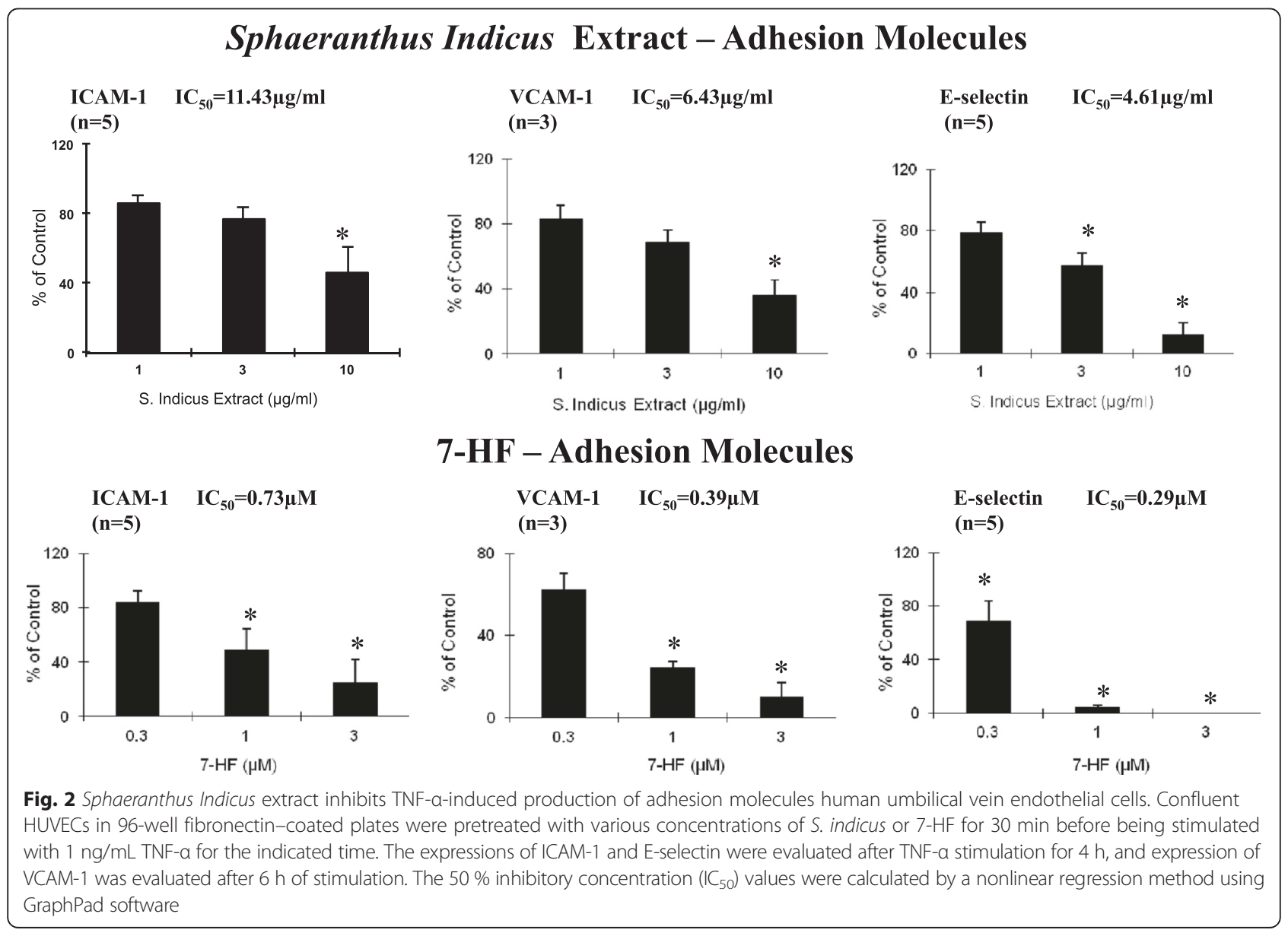



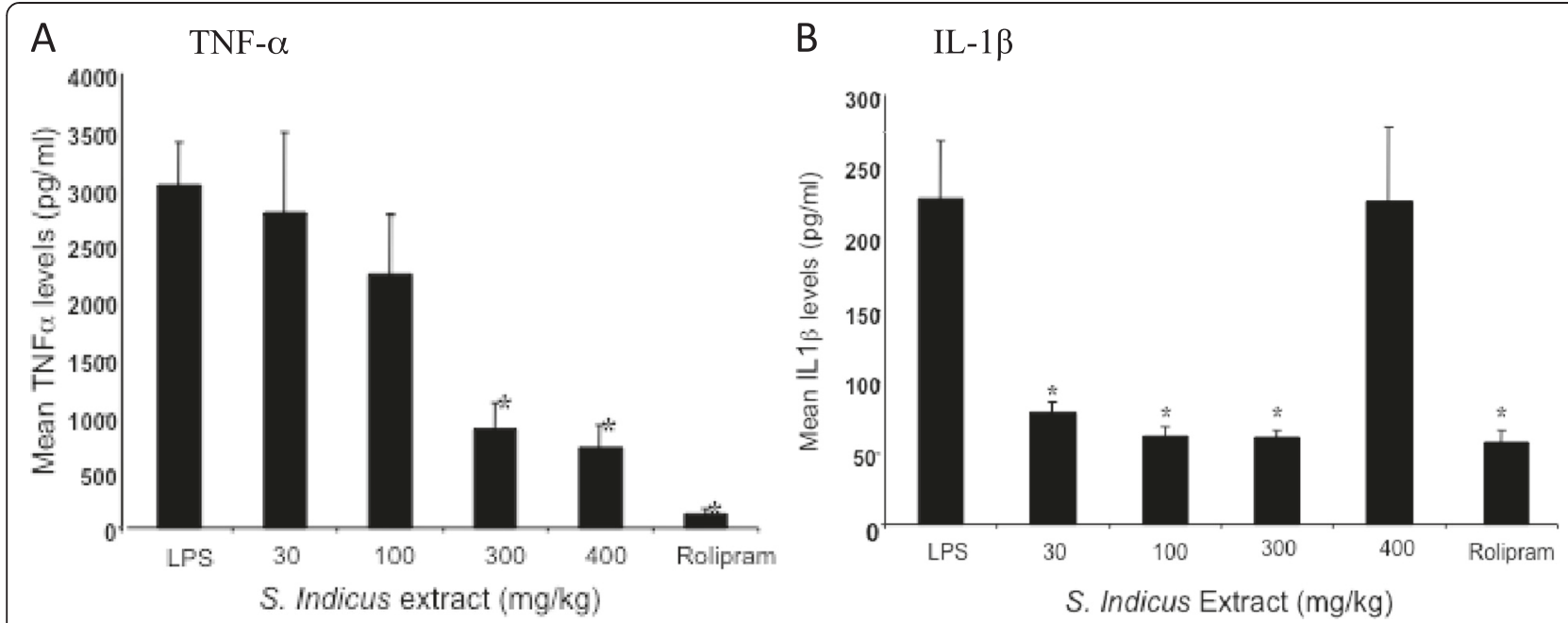

Fig. 3 a Sphaeranthus Indicus extract inhibits lipopolysaccharide-induced TNF-a production in mice. Groups of 10 mice were treated orally with Sphaeranthus Indicus methanolic extract, 60 min prior to lipopolysaccharide injection (1 mg/kg, i.p.). Levels of TNF-a in the plasma were measured $1.5 \mathrm{~h}$ after lipopolysaccharide injection. Results are expressed as the mean \pm S.E.M. ${ }^{*} P<0.001$ significantly different from LPS control (students $t$ test). $\mathbf{b}$ Sphaeranthus indicus extract inhibits lipopolysaccharide-induced IL-1 $\beta$ production in mice. Groups of 10 mice were treated orally with S. indicus 60 min prior to lipopolysaccharide injection ( $2 \mathrm{mg} / \mathrm{kg}$, i.p.). Amounts of IL-1 $\beta$ in the plasma were measured 4 h after lipopolysaccharide injection. Results are expressed as the mean \pm S.E.M. ${ }^{*} P<0.001$ significantly different from LPS control (students $t$ test)

inhibition of TNF- $\alpha$ production with $300 \mathrm{mg} / \mathrm{kg}$ dose of S. indicus extract showing maximal inhibition ( $80 \%)$. Rolipram, used as a reference agent, showed robust inhibition of LPS-induced TNF- $\alpha$ production. The effect of $S$. indicus extract on IL- $1 \beta$ was found to be even more robust (Fig. 3b), showing $>60 \%$ inhibition at $30 \mathrm{mg} / \mathrm{ml}$ concentration, which was as effective as rolipram. Heat inactivated and denatured extract (400 mg/kg dose) did not show any efficacy.

\section{Effect of S. indicus extract and 7-HF on NF-KB activation by TNF-a}

The TNF- $\alpha$ induced expression of adhesion molecules ICAM-1, VCAM-1 and E-selectin requires the transcription factor NF- $\mathrm{kB}[36,37]$. NF- $\mathrm{kB}$ is also involved in the inflammatory diseases like arthritis [38] and psoriasis [39]. Therefore, we studied the effect of $S$. indicus extract and 7-HF on the nuclear translocation of the NF-kB p65. We carried out Western blot analysis to determine the levels of NF- $\mathrm{kB}$ p65 in the cytoplasmic and nuclear extracts from HUVEC treated with TNF- $\alpha$ in the presence or absence of $S$. indicus extract and 7-HF. As shown in Fig. 4a \& b, TNF- $\alpha$ induced nuclear translocation of NF-kB p65 occurs within 15 min (Lane 4). In contrast, $S$. indicus extract and $7-\mathrm{HF}$, at a concentration of $15 \mu \mathrm{g} / \mathrm{ml}$ and $3 \mu \mathrm{M}$ respectively, decreased the amount of nuclear NF- $\mathrm{B}$, with a concurrent increase in the amount of cytoplasmic NF-кB (Fig. 4a). Thus, $S$. indicus extract and 7-HF completely abolished nuclear translocation of NF- $\mathrm{kB}$ p65. Although equal amount of protein was taken for Western blotting, which was determined by a linear curve obtained from amount of protein loaded and the respective protein band intensity, these results should be interpreted cautiously.

\section{Effect of S. indicus extract and 7-HF on TNF-a-induced phosphorylation and degradation of IKBa}

TNF- $\alpha$-induced regulation of NF- $\kappa B$ involves the phosphorylation, ubiquitination and degradation of the cytoplasmic inhibitor, IкB- $\alpha$ [40]. To determine whether $S$. indicus extract and 7-HF inhibits NF- $\mathrm{B}$ activation due to an effect on the phosphorylation and/or degradation of $I_{\kappa} B \alpha$, the cytoplasmic I $\mathrm{B} \alpha \alpha$ protein levels were examined by Western blot analysis. The results show that a $37-\mathrm{kDa}$ protein was detected in the cytoplasmic extract of untreated cells at time $0 \mathrm{~min}$ (Fig. 5a, lane 1) whereas TNF- $\alpha$ treatment caused a loss of IкB- $\alpha$ after $15 \mathrm{~min}$ (Fig. 5a, lane 3). Thereafter, IкB- $\alpha$ was reactivated 60 min onwards (Fig. 5a, lane 5 and 6), possibly by NF$\kappa B$, as NF- $\kappa B$ is known to bind and activate the $I \kappa B-\alpha$ promoter. The pretreatment of cells with $S$. indicus extract at $15 \mu \mathrm{g} / \mathrm{ml}$ completely abolished TNF- $\alpha$-induced degradation of IkB- $\alpha$ (Fig. 5a, lane 3 and 4), but 7-HF did not show similar results (Fig. 5a, lane 3 and 4). In fact, IKB- $\alpha$ was not resynthesized even after $60 \mathrm{~min}$ in presence of 7-HF (Fig. 5a, lane 5 and 6). This is not surprising since inhibition of NF- $\mathrm{kB}$ activity would also inhibit the regeneration of $I_{\kappa} B-\alpha$ mRNA.

To ascertain whether $S$. indicus extract inhibits IkB- $\alpha$ degradation by blocking its phosphorylation, the cyoplasmic extracts were examined by western blot analysis using antibodies that detect only the serine- 
A

\section{Cytosolic Extracts}
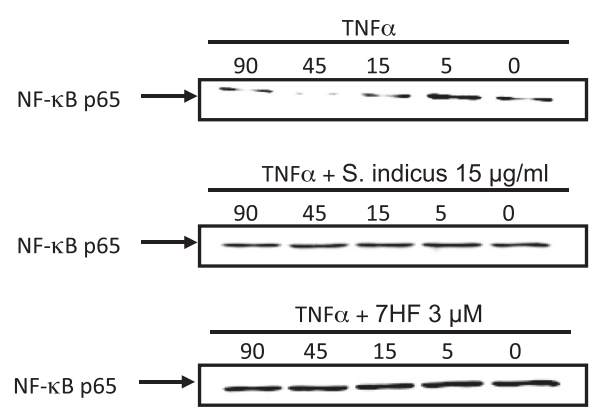

$\begin{array}{llllll}\text { Lane } & 5 & 4 & 3 & 2 & 1\end{array}$

\section{B}

Nuclear Extracts
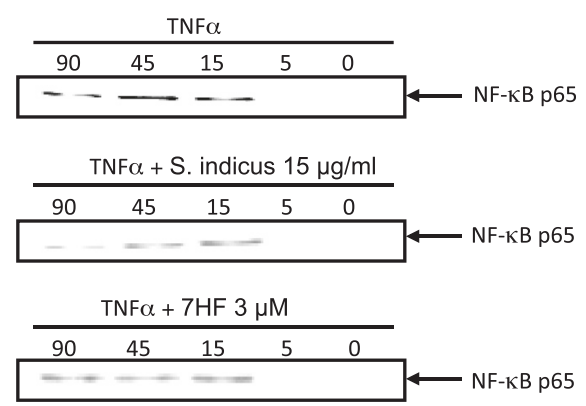

$\begin{array}{lllll}5 & 4 & 3 & 2 & 1\end{array}$

Fig. 4 Effect of S. indicus extract and $7 \mathrm{HF}$ on the nuclear translocation of NF-kB p65 in TNF-a-stimulated HUVECs. Briefly, confluent HUVEC monolayers were pretreated with $15 \mu \mathrm{g} / \mathrm{mL}$ S. indicus extract or $3 \mu \mathrm{M} 7 \mathrm{HF}$ for $1 \mathrm{~h}$ followed by stimulation with $0.1 \mathrm{nM}$ TNF-a for the time points. The cytosolic (Panel a) as well as nuclear (Panel b) extracts were prepared (as described in materials and methods) and analyzed by Western blot analysis with a primary antibody against human NF-kB p65 (3 independent experiments). Upper row shows treatment with TNF-a, middle rows shows treatment with TNF- $a+S$. indicus extract, and lower row shows TNF- $a+7-H F$

phosphorylated form of IкB- $\alpha$. The results show that the serine phosphorylated form of $\mathrm{I} \kappa \mathrm{B} \alpha$ appears at 15 and $30 \mathrm{~min}$ (Fig. 5b, lanes 3 and 4), which completely disappeared when cells were pretreated with $S$. indicus extract (Fig. 5b, lanes 3 and 4), indicating that it completely abolished the TNF- $\alpha$ induced phosphorylation of IкB- $\alpha$. However, the cells pretreated with 7-HF did not show similar results. While the differences in the untreated and treated groups are evident when equal amounts of protein was loaded to each lane, it should be noted that internal control was not included. Nevertheless, the results do indicate inhibition of $\mathrm{I} \kappa \mathrm{B} \alpha$ phosphorylation.

Taken together, the cell ELISA and Western blot analysis, suggest that $S$. indicus extract inhibits TNF$\alpha$-induced $I \kappa \mathrm{B} \alpha$ phosphorylation and degradation, which causes a decrease in NF- $\mathrm{kB}$ resulting in decreased surface expression of adhesion molecules. In contrast, 7-HF, one of its bioactive principles, without affecting the phosphorylation and degradation of IкB- $\alpha$, inhibits

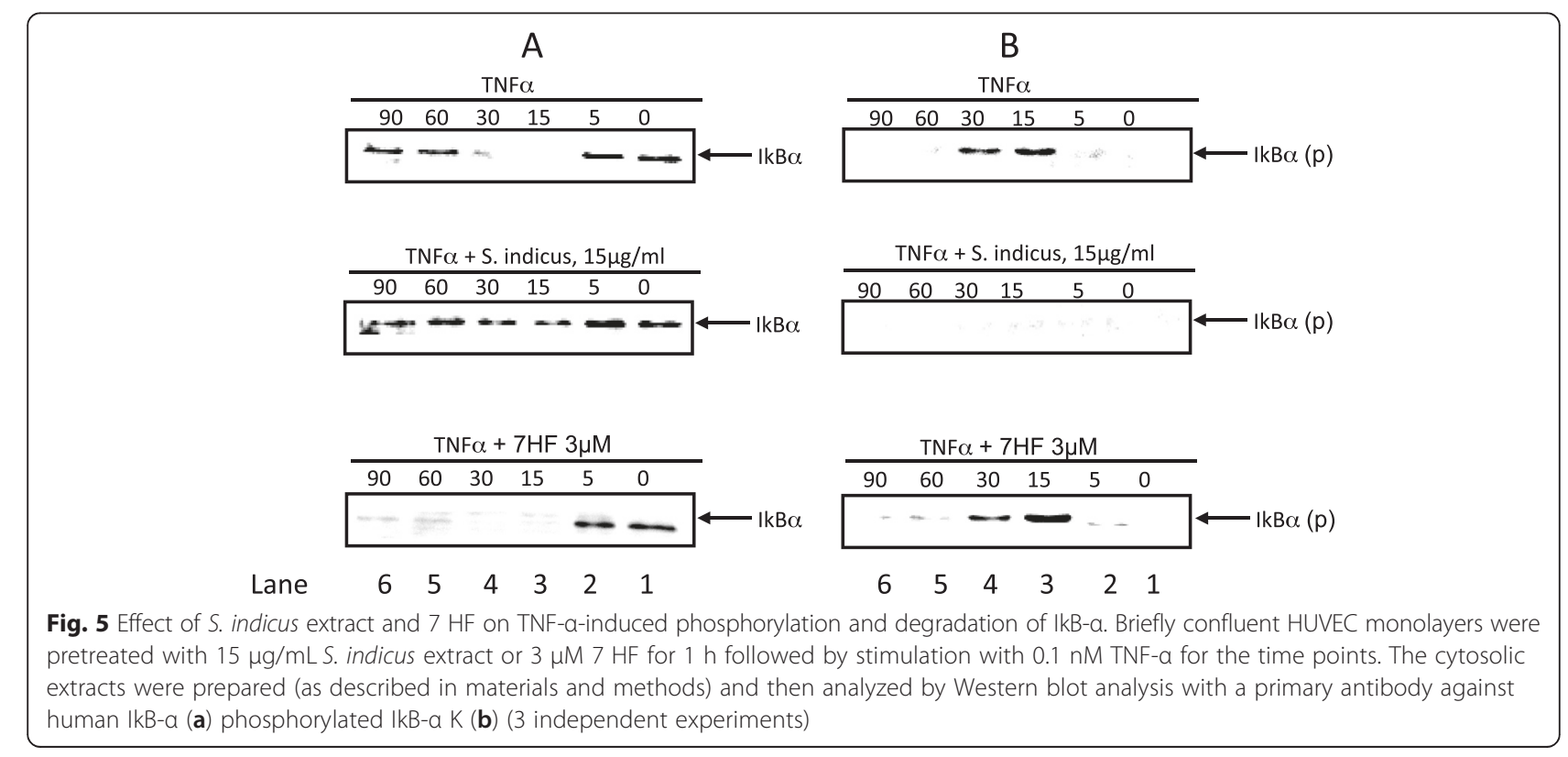




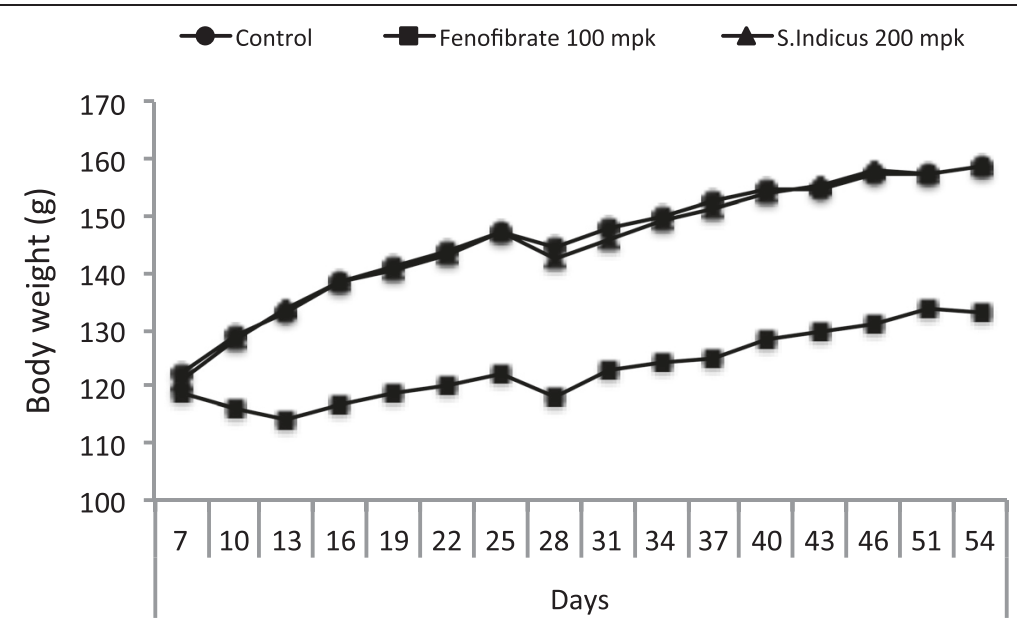

Fig. 6 Effect of S. indicus on body weight in diet-induced hyperlipidemic hamsters. Body weight measurements were carried out 18 times at the interval of 3 days during the course of 60 days study

the activation of NF- $\mathrm{BB}$ thereby reducing the surface expression of adhesion molecules.

\section{Effect of S. sphaericus extract on plasma lipids and} atherosclerosis in hamsters

Feeding high fat high cholesterol diet caused gradual increase in body weight (Fig. 6), showing a $30 \%$ increase after 59 days. The treatment group showed no difference in body weight gain on high fat high cholesterol diet during the same period, suggesting that there was no adverse effect of the $S$. indicus extract treatment up to $200 \mathrm{mg} / \mathrm{kg}$ body weight/day in hyperlipidemic hamsters. The total cholesterol and triglycerides rose to $1700 \mathrm{mg} / \mathrm{dl}$ and $2200 \mathrm{mg} / \mathrm{dl}$, respectively (Fig. 7). The hamster model

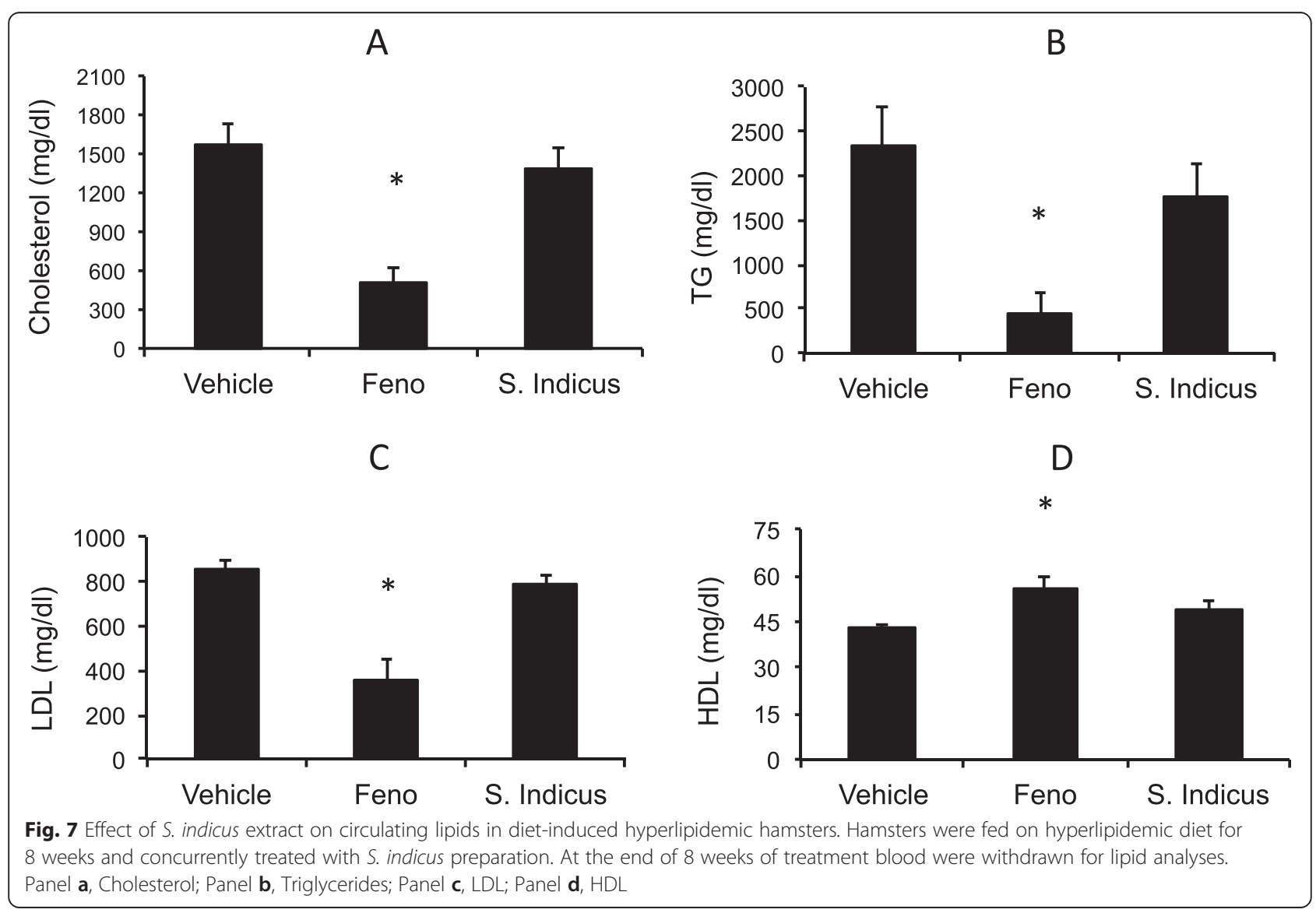


of atherosclerosis is hyperlipidemia driven [31, 33]. The total cholesterol and LDL-C remained unchanged in the $S$. indicus extract treated group, however, there was a small change in triglyceride level. Fenofibrate, known to lower lipids in the hyperlipidemic hamsters [31, 33], showed similar hypolipidemic effect with massive reductions in total cholesterol, triglycerides and LDL-C (Fig. 7a-d). Since insulin resistance and diabetes may also influence arterial lipid deposition [41], we measured plasma levels of glucose shown in Fig. 8. There was a modest decrease in the glucose levels in S. indicus extract treated as well as fenofibrate treated groups.

In the control vehicle treated hamsters, $0.5 \%$ of the aorta was found to have lesions (Fig. 9). Fenofibrate, included as a reference agent, reduced lesion area by more than $80 \%$. This reduction in lesion area was associated with massive reductions in proatherogenic lipoproteins. Treatment with $S$. indicus extract reduced aortic lesion by more than $40 \%$ without changes in the proatherogenic lipoproteins.

\section{Effect of S. sphaericus extract on plasma lipids and atherosclerosis in $\mathrm{LDLr}^{-/-}$mice}

Anti-atherosclerotic and anti-hyperlipidemic activities of $S$. indicus extract were also evaluated in a mouse model of atherosclerosis at two concentrations, 100 and $300 \mathrm{mg} / \mathrm{kg} / \mathrm{d}$. While there was no change in body weight at $100 \mathrm{mg} / \mathrm{kg} / \mathrm{d}$ dose (Fig. 10), a non-significant increase in body weight was noticed at $300 \mathrm{mg} / \mathrm{kg} / \mathrm{d}$ dose, suggesting that this high dose was safe in animal model of atherosclerosis. As expected [30], fenofibrate prevented body weight gain. Feeding high fat high cholesterol diet raised total cholesterol and triglycerides $\sim 1200$ and $\sim 600 \mathrm{mg} / \mathrm{dl}$, respectively (Fig. 11). While fenofibrate decreased proatherogenic lipoproteins and triglycerides, $S$. indicus preparation did not change circulating lipoproteins and triglycerides (Fig. 11). Since a high dose of $S$. indicus preparation was used in this study, we also measured some of the parameters indicative of safety. As shown in Fig. 12, no significant changes were observed in AST and ALT levels.

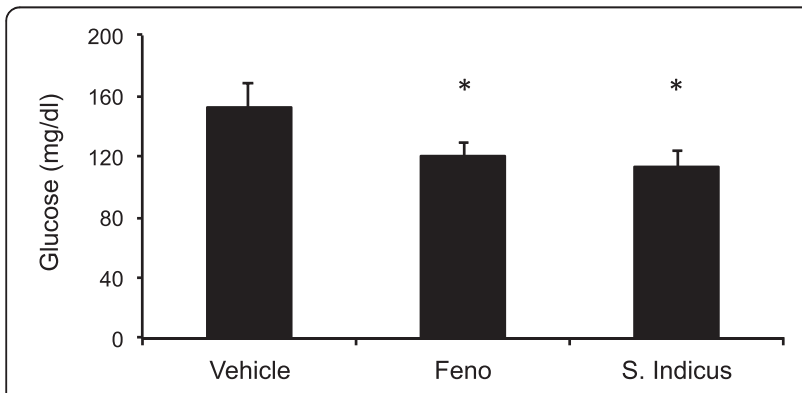

Fig. 8 Effect of S. indicus extract on plasma glucose in diet-induced hyperlipidemic hamsters
High fat and cholesterol feeding to $\mathrm{LDLr}^{-/}$mice caused almost $4 \%$ coverage of aorta with lipids as measured by neutral lipid staining. Treatment with fenofibrate showed a reduction of $26 \%$ in lipid staining. $S$. indicus preparation reduced lesion area by $22 \%$ at $100 \mathrm{mg} / \mathrm{kg} /$ day dose. Increasing the dose of $S$. indicus preparation did not show any advantage either in terms of overall lipid profile or the extent of reductions in lesion area (Fig. 13).

\section{Effect of S. sphaericus extract on cytokines in $\mathrm{LDLr}^{-/-}$mice}

To evaluate anti-inflammatory efficacy in atherosclerosis model, we measured circulating pro-inflammatory cytokines and adhesion molecules to ascertain its role in anti-atherosclerotic properties. Since IL-6 is a proinflammatory cytokine [42] and MCP-1, a cell adhesion molecule and a proatherogenic marker [43], we measured these two proteins in the serum. As shown in Fig. 14, there was 4-fold increase in the levels of MCP-1 as a result of high fat and cholesterol feeding, which decreased more than 2-fold following treatment with $100 \mathrm{mg} / \mathrm{kg} /$ day of $S$. indicus preparation. High fat high cholesterol diet caused only modest increases in IL-6 levels, however, treatment with $S$. indicus preparation caused significant reduction $(\sim 50 \%)$ at $100 \mathrm{mg} / \mathrm{kg} /$ day dose and $75 \%$ reduction at $300 \mathrm{mg} / \mathrm{kg} /$ day dose. To assess if the changes in MCP-1 occurred as a result of transcriptional activation, RNA from aorta was prepared and MCP-1 mRNA quantitated. There was a 2.5 -fold increase in the aortic MCP-1 mRNA in the vehicle treated group when compared to MCP-1 level at the start of the high fat feeding, which decreased by $40 \%$ following treatment with S. indicus preparation (Fig. 15). Fenofibrate treatment also showed similar reductions in MCP-1. Since the levels of TNF- $\alpha$ could not be reliably measured in the plasma because of low levels, we attempted to measure TNF- $\alpha$ mRNA in the RNA prepared from aorta. The results of TNF- $\alpha$ measurements shown in Fig. 15 suggest that high fat feeding does increase TNF- $\alpha$ mRNA in the aorta by $\sim 3$-fold. Treatment of high fat-fed $\mathrm{LDLr}^{-/-}$mice with $S$. indicus preparation caused a $\sim 30 \%$ reduction in TNF- $\alpha$ mRNA. Both IL-6 and IL1- $\beta$ did not show significant changes (data not shown).

\section{Discussion}

In the course of screening natural products to find novel anti-inflammatory drugs as TNF- $\alpha$ inhibitors we found that $S$. indicus extract and $7-\mathrm{HF}$, one of its active constituents, characterized as a sesquiterpene lactone, suppresses the cytokine production in a concentration-dependent manner from LPS-stimulated human peripheral blood mononuclear cells as well as from synovial cells obtained from rheumatoid arthritis patients 


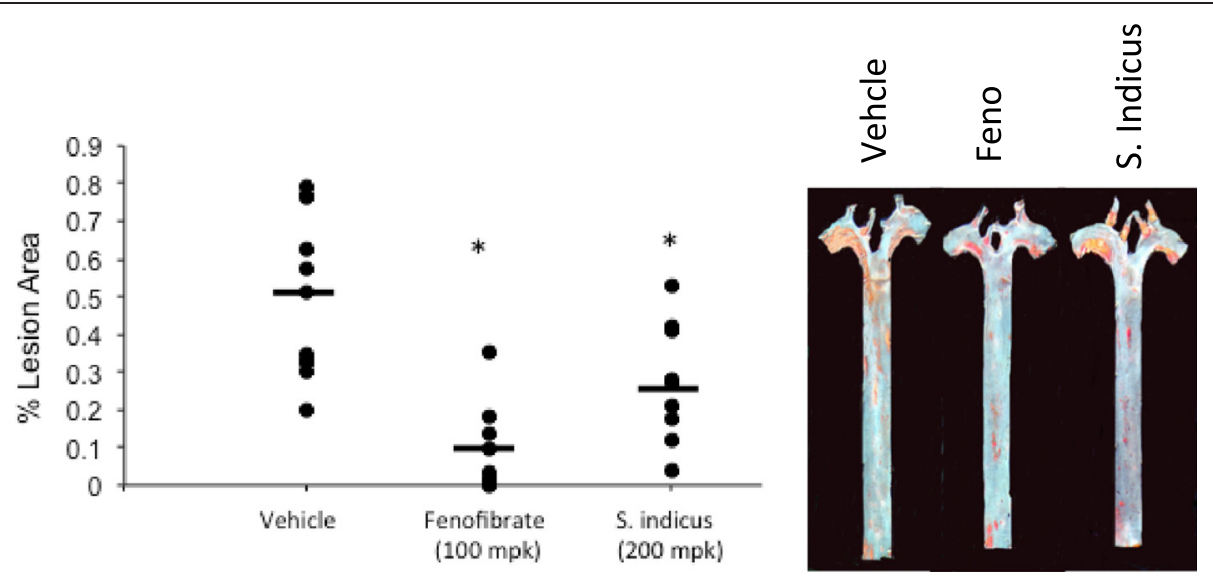

Fig. 9 Effect of S. indicus extract on aortic lipid deposition in diet-induced hyperlipidemic hamsters. Animals were fed high fat high cholesterol diet and concomitantly dosed by oral gavage At the end of 10 weeks of treatment, hamsters were euthanized under $\mathrm{CO}_{2}$ and blood withdrawn by cardiac puncture and processed plasma lipid and glucose analysis. Their thorax was opened and vasculature perfused first with heparinized saline then with $10 \%$ formalin. The aorta attached to heart and containing aortic arch, thoracic and abdominal aorta to the femoral artery bifurcation were removed and placed in $10 \%$ formalin for en face staining and lesion quantitation. Aortic lipid contents were quantitated by en face staining with Oil Red $\mathrm{O}$ and atherosclerotic lesion area coverage determined by image analysis

undergoing knee replacement surgery. Most importantly, S. indicus extract was also found to arrest disease progression in an in vivo mouse model for rheumatoid arthritis [29]. Since atherosclerosis is an inflammatory disease [44], we sought to investigate if anti-inflammatory activities of $S$. indicus inhibited atherosclerosis progression. We also looked into the mechanism of anti-inflammatory properties of S. indicus.

It has been previously documented that sesquiterpene lactones or sesquiterpene lactone-containing plant extracts exert potent anti-inflammatory effect, at least in part, through inhibition of transcription factor NF-kB [45], causing a decrease in adhesion molecule expression and subsequent leukocyte adhesion. Here, we show that natural product, $S$. indicus extract along with one of its active constituent, 7-HF mediate anti-inflammatory effects by effectively modulating the expression of cell adhesion molecules via suppression of $\mathrm{NF}-\mathrm{kB} / \mathrm{I} \kappa \mathrm{B} \alpha$ signaling in TNF- $\alpha$ activated HUVECs.

Clearly, S. indicus extract (at the dose of $10 \mu \mathrm{g} / \mathrm{ml}$ ) significantly inhibited the expression of the ICAM-1 (54 \% inhibition), VCAM-1 (64\% inhibition), and E-selectin (88\% inhibition) in TNF- $\alpha$ activated HUVECs (Fig. 2). Likewise, 7-HF, a sesquiterpene lactone, (at the dose of $3 \mu \mathrm{M})$ dramatically inhibited ICAM-1 (75 \% inhibition), VCAM-1 (90\% inhibition), and E-selectin (100\%

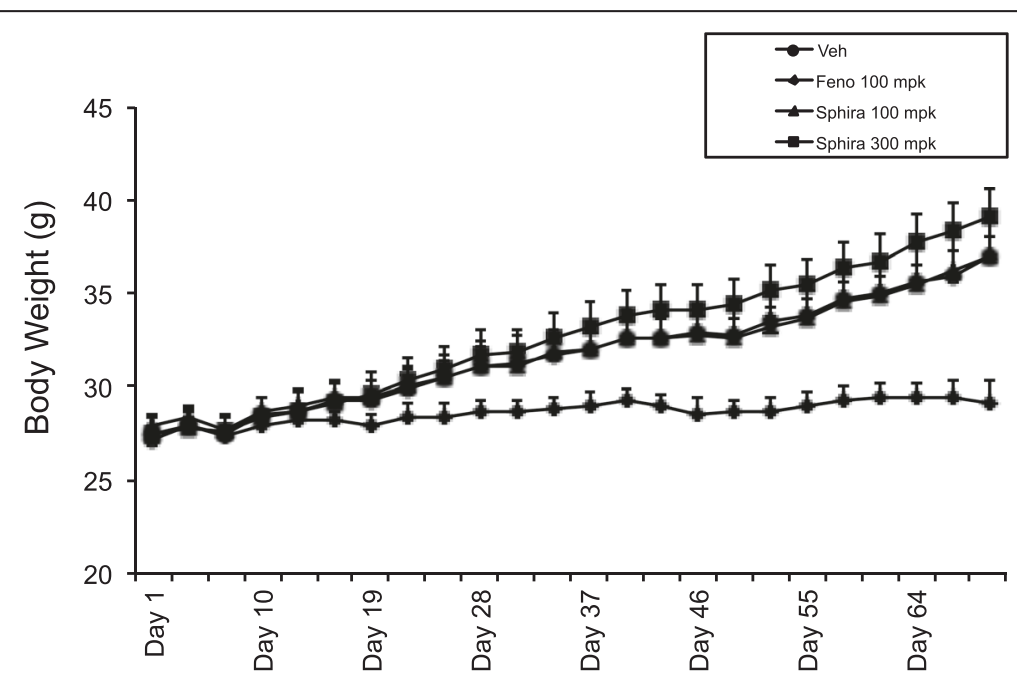

Fig. 10 Effect of S. indicus on body weight in diet-induced hyperlipidemic LDL receptor-deficient mice. Body weight measurements were carried out at the interval of 3 days during the course of study 


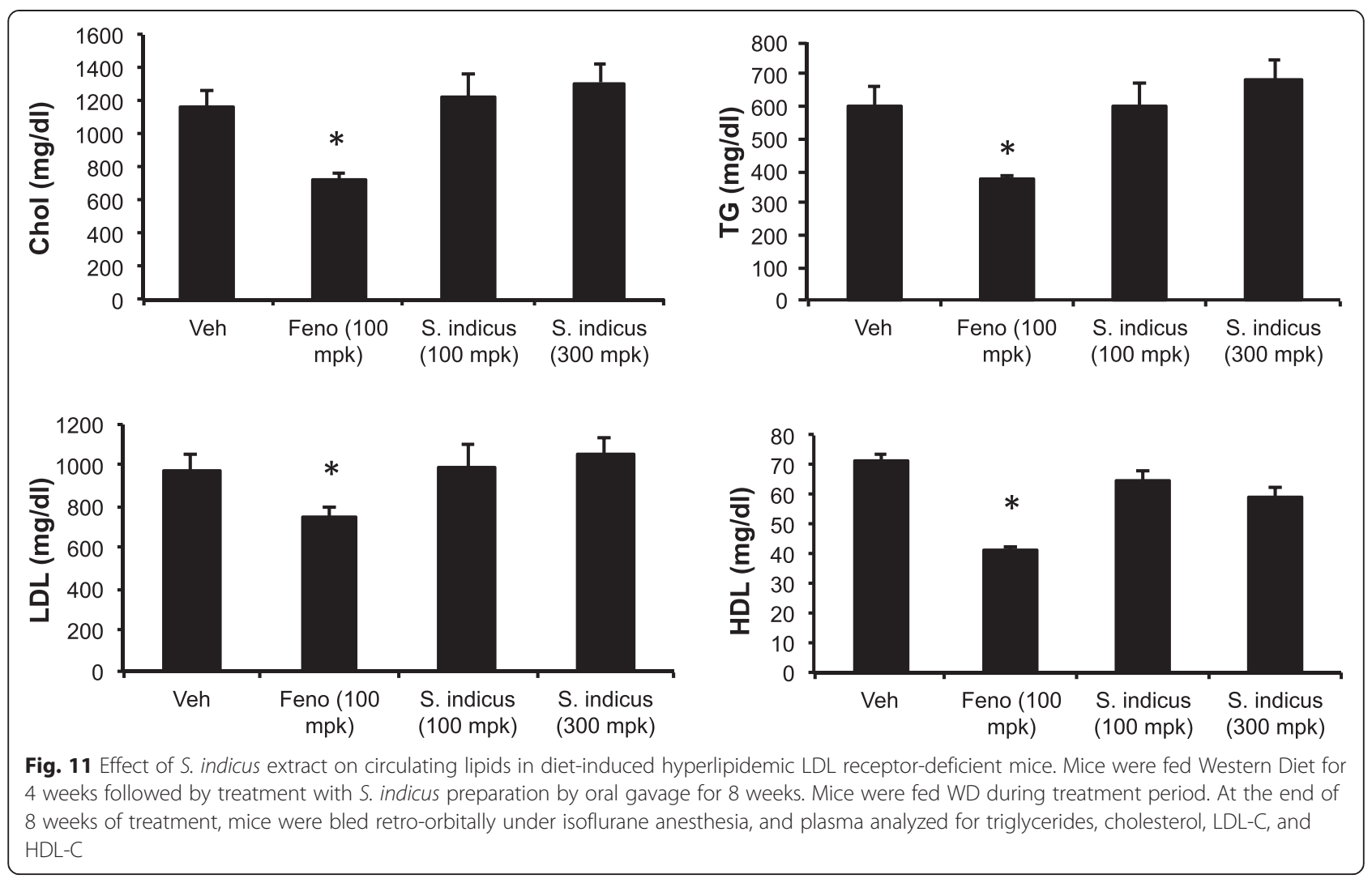

inhibition) in TNF- $\alpha$ treated HUVECs (Fig. 2). Similar effects with compounds such as 1,4-Dihyroxyxanthone $(65 \mu \mathrm{g} / \mathrm{mL})$ [46], diclofenac $(750 \mu \mathrm{M})$ [47], pyrrolidine dithiocarbamate $(1 \mathrm{mM})$ [48] and $\mathrm{N}$-acetyl cysteine $(100 \mu \mathrm{M})$ [49] on cytokine-induced expression of cell adhesion molecules have been demonstrated by previous investigators, albeit at higher concentrations. Interestingly, S. indicus extract and one of its bioactive components, 7-HF, were found to be effective at comparatively lower concentrations and therefore, may be used in controlling various pathological conditions associated with upregulation of endothelial leukocyte adhesion molecules such as atherosclerosis, bacterial sepsis, inflammation and tumor metastasis.

To further delineate the mechanism by which $S$. indicus extract and 7-HF may be acting, we studied its effect on NF- $\mathrm{kB}$ activation. Using Western blot analysis, we show that $S$. indicus extract and 7-HF both appear to block TNF- $\alpha$ induced p65 translocation from the cytoplasm to the nucleus. In this respect, 7-HF possibly behaves differently from other known sesquiterpene lactones [45] such as helenalin [50], parthenolide [51] and isodeoxyelephantopin [52], which exert their antiinflammatory effect by either targeting the ІкB kinase complex or inhibiting the DNA binding of p65 homodimer. The mode of action of 7-HF appears to be similar to compounds like caffeic acid phenethyl ester (CAPE) [53] and DHMEQ [54], which block $\mathrm{NF} \times \mathrm{B}$ by inhibiting its binding to promoter DNA without affecting the degradation of IкB- $\alpha$. Because NF- $\kappa B$ is responsible for the induced expression of ICAM- 1 , VCAM-1 and E-selectin [55], these results suggest that both these agents inhibit NF-kB dependent transcription of cell adhesion molecule genes. However, it is quite possible that $S$. indicus extract and $7 \mathrm{HF}$ may also inhibit other transcription factors.

In addition, we also showed that pretreatment of cells with proteasome inhibitor ALLN prevents the destruction of IKB- $\alpha$ and results in accumulation of phosphorylated IкB- $\alpha$. On the other hand, treatment of cells with $S$. indicus extract did not result in the accumulation of phosphorylated IKB- $\alpha$ in the cytoplasm. This led us to conclude that $S$. indicus extract possibly prevents NF- $\mathrm{kB}$ by preventing phosphorylation of I $\mathrm{K} B-\alpha$ rather than proteolysis per se [40]. It is well known that the pathway leading to activation of NF- $\mathrm{kB}$ is common for these activators, implying that $S$. indicus extract acts at a molecular step common to both the LPS- and TNF pathways, which could be at the level of IKK or upstream of IKK. The effect of $S$. indicus extract on the cascade 


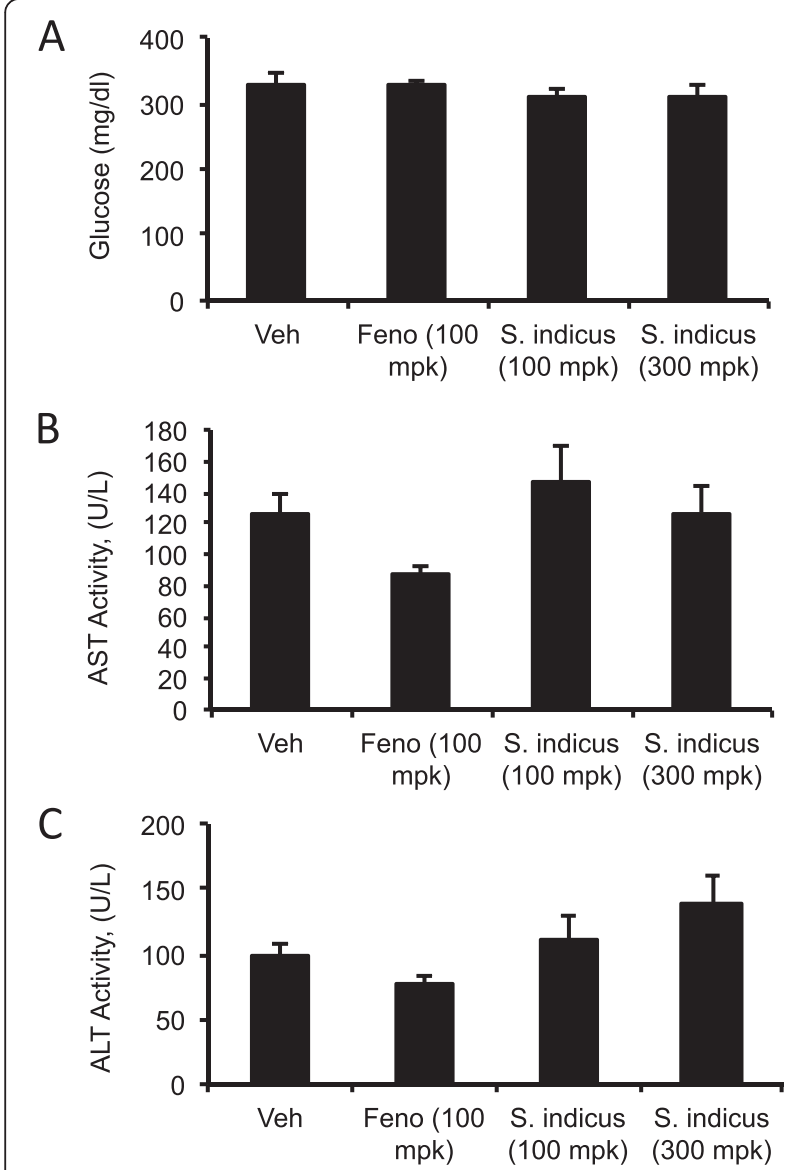

Fig. 12 Effect of $S$. indicus extract on plasma glucose and markers of liver toxicity in diet-induced hyperlipidemic LDL receptor-deficient mice. Panel a, Glucose; Panel b, AST; Panel c, ALT upstream of IKK remains to be clarified, although it is quite possible that $S$. indicus extract may suppress different steps in the NF- $\mathrm{kB}$ activation pathway.

The standardized $S$. indicus extract $(10 \mu \mathrm{g} / \mathrm{ml})$ contains approximately $0.6 \mu \mathrm{g} / \mathrm{ml}$ or $3 \mu \mathrm{M}$ of $7-\mathrm{HF}$, and since we observed similar effects of $S$. indicus extract at $10 \mu \mathrm{g} / \mathrm{ml}$ and 7 -HF at $3 \mu \mathrm{M}$ (data not shown), we postulated that the effects on the expression of cell adhesion molecules and NF-kB activation seen with the crude extract of $S$. indicus extract may be related to its content of 7-HF. However, there are as yet uncharacterized active components besides 7 -HF, which may be responsible for the additional potency of $S$. indicus extract that is reflected in the inhibition of IKB- $\alpha$ phosphorylation and degradation.

Thus, S. indicus extract and 7-HF a) significantly reduced ICAM-1, VCAM-1 and E-selectin expression; b) markedly inhibits the translocation of p65 from cytoplasm to the nucleus; and c) inhibits IкB- $\alpha$ phosphorylation and degradation. These activities of $S$. indicus extract and 7-HF suggest its potential to treat a wide variety of NF- $\mathrm{kB}$-linked pro-inflammatory diseases such as rheumatoid arthritis, atherosclerosis and inflammatory bowel disease.

We, therefore, evaluated anti-atherosclerotic activities of $S$. indicus preparation in two widely studied animal models of atherosclerosis. Based on our in vitro results, we chose a dose equivalent to $120 \mathrm{mg} / \mathrm{kg} /$ day of active ingredient, 7-HF to examine the potential of $S$. indicus preparation to treat atherosclerosis. Both hamster and the $\mathrm{LDLr}^{-1-}$ mice showed efficacy in terms of slowing down atherosclerosis progression without modulating circulating proatherogenic lipoproteins, suggesting that the reductions in lesion area was not due to proatherogenic lipoproteins, but other mechanism(s). This effect was very different than those observed with fenofibrate, where reductions in lesion area were associated with

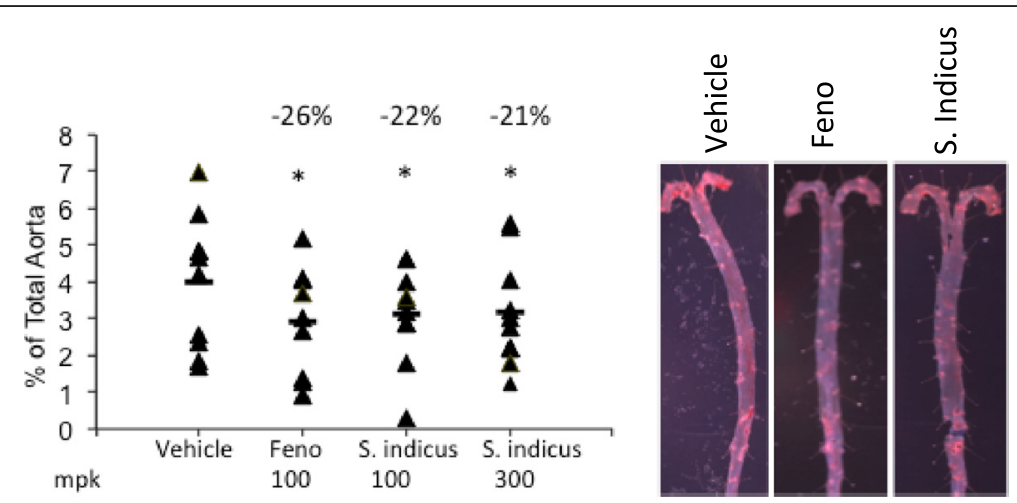

Fig. 13 Effect of S. indicus extract on aortic lipid deposition in diet-induced hyperlipidemic LDL receptor-deficient mice. Mice were fed Western Diet for 4 weeks followed by treatment with $S$. indicus preparation by oral gavage for 8 weeks. Mice were fed WD during treatment period. At the end of 8 weeks of treatment, mice were bled retro-orbitally under isoflurane anesthesia, sacrificed by carbon dioxide asphyxiation, and aorta removed and processed for Oil Red O staining 


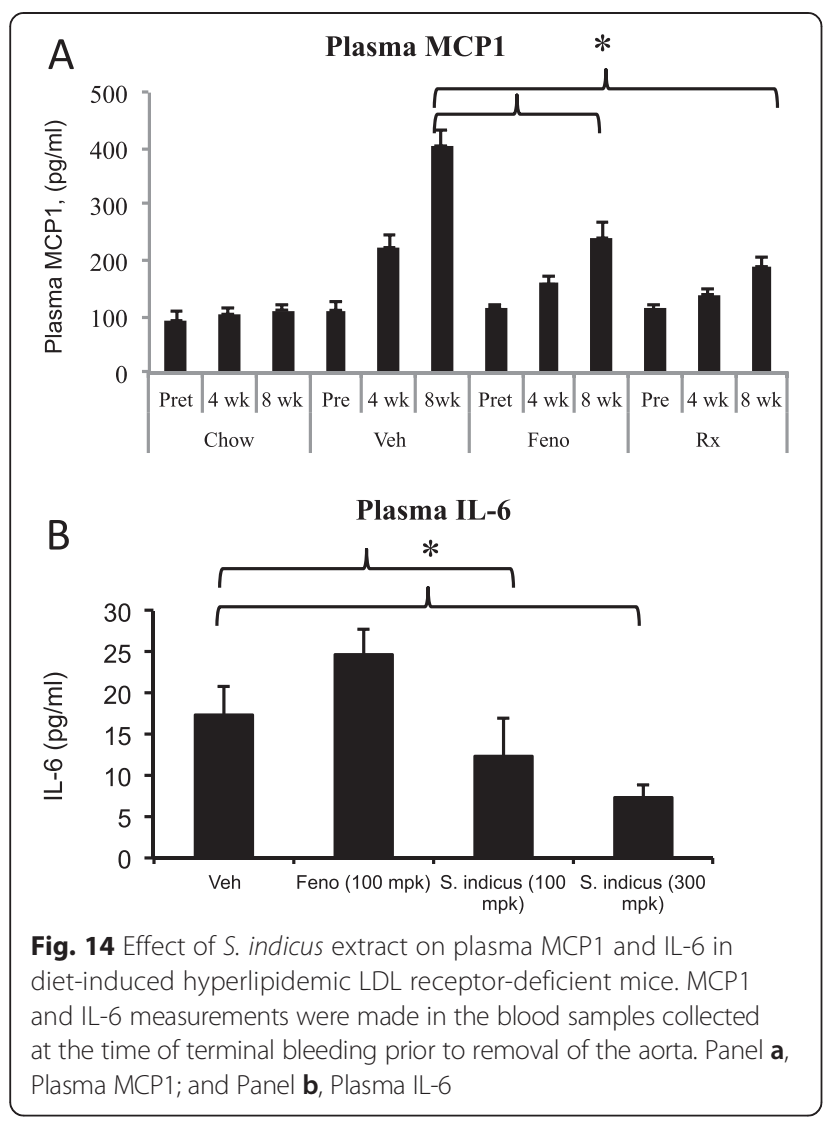

reductions in proatherogenic lipoproteins in hamsters [33] as well as in $\mathrm{LDLr}^{-1-}$ mice [30]. Reductions in IL-6, TNF- $\alpha$, and MCP-1 do suggest that $S$. indicus preparation decreased aortic lipid deposition by reducing circulating pro-inflammatory cytokines. These data are consistent with in vitro cell-based findings that showed NFkB-mediated down-regulation of pro-inflammatory cytokines and adhesion molecules. Natural products that inhibits NF-kB pathway lower cell adhesion molecules and pro-inflammatory cytokines, leading to reduced atherosclerotic burden [56-58] without changes in circulating lipoprotein levels.

We hypothesized that anti-inflammaory agents showing efficacy in inflammatory diseases like psoriasis, colitis and rheumatoid arthritis will inhibit atherosclerosis progression. Indeed, individuals with psoriasis [18, 20, 59-62], inflammatory bowel disease [63], and rheumatoid arthritis $[22,25,64-67]$ have greater risks of developing coronary artery disease. These findings together with chronic inflammation in atherosclerosis [5, 68] and end stage kidney disease in diabetics [69] have led to increasing efforts to discover and develop anti-inflammatory agents to treat coronary artery disease [70]. NFkB inhibitors are among anti-inflammatory agents showing antiatherosclerotic activities [57, 58, 71]. High-density lipoproteins shown to regress atherosclerosis is believed to have an aniinflammatory component [72], in addition to promoting reverse cholesterol transport [73]. The antiatherosclerotic activities of many of the natural products like alicin [74], catechins [75], abscisic acid [76], marinederived wax esters [77], dried plums [78], and a number of plant-derived flavonoids [79], are attributed to their antiinflammatory activities. The anti-atherosclerosis efficacy of $S$. indicus preparation in the present study is not surprising, as a number of anti-inflammatory agents possess anti-atherosclerosis activities via NF-kB mediated pathways $[57,58,71]$. Sesquiterpene lactones have been shown in $\mathrm{apoE}^{-1-}$ mice and guinea pigs to have antiatherosclerosis efficacy via their anti-inflammatory activities [80, 81]. Here we showed that S. indicus preparation with major ingredient 7-HF, a sesquiterpene lactone, inhibited atherosclerosis progression in

MCP1, TNF-alpha mRNA

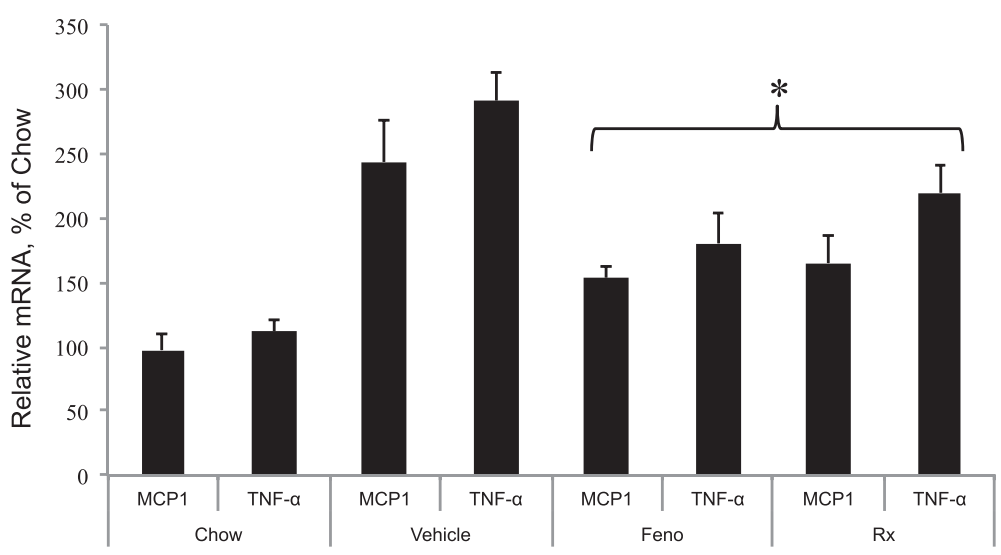

Fig. 15 Effect of S. indicus extract on aortic MCP1 and TNF-a mRNA in diet-induced hyperlipidemic LDL receptor-deficient mice. Aortae from 3 animals from each group were not subjected to OilRed O staining. These aortae were used to prepare total RNA for the quantitation of MCP1 and TNF-a mRNA 
two diet-induced atherosclerosis models, LDLr knockout and hamsters.

In summary, we showed that the main component of $S$. indicus preparation, 7-HF, is an anti-inflammatory agent that works through NF-kB-mediated pathway, and inhibits atherosclerosis progression. These findings offer promise for further clinical benefits to patients with inflammatory and cardiovascular diseases.

\section{Competing interests}

The authors declare that they have no competing interests.

\section{Authors' contributions}

RAS designed and executed atherosclerosis studies in hamsters and LDLr KO mice, did interpretation of the data, and wrote the manuscript. SM designed and carried out screening assays and Nf-kB studies, and SS provided input in the design of studies. All authors read and approved the final manuscript.

\section{Acknowledgements}

The authors would like to thank Roda Dalal and Aurellio Lobo for their excellent technical support, and to Piramal Life Sciences, Mumbai for research facility.

\# Part of the studies reported here was presented at the International Atherosclerosis Society, Boston, June, 2009.

\section{Author details}

'Department of Pharmacology, Piramal Life Sciences Ltd, Mumbai, India. ${ }^{2}$ Present address: Integrated Pharma Solutions, Philadelphia, Department of Pharmacology \& Physiology, Drexel University School of Medicine, Philadelphia, USA. ${ }^{3}$ Present address: BioMarin Pharmaceuticals, Novato, CA, USA

Received: 9 February 2015 Accepted: 29 May 2015

Published online: 05 June 2015

\section{References}

1. Ross R. Atherosclerosis: current understanding of mechanisms and future strategies in therapy. Transplant Proc. 1993;25:2041-3.

2. Ross R. Atherosclerosis is an inflammatory disease. Am Heart J. 1999:138:S419-20.

3. Libby P. Inflammation in atherosclerosis. Nature. 2002;420:868-74.

4. Libby P. Inflammation and cardiovascular disease mechanisms. Am J Clin Nutr. 2006:83:456S-60.

5. Libby P, Crea F. Clinical implications of inflammation for cardiovascular primary prevention. Eur Heart J. 2010;31:777-83.

6. Rader DJ, Daugherty A. Translating molecular discoveries into new therapies for atherosclerosis. Nature. 2008;451:904-13.

7. Cybulsky Ml, liyama K, Li H, et al. A major role for VCAM-1, but not ICAM-1, in early atherosclerosis. J Clin Invest. 2001;107:1255-62.

8. Li H, Cybulsky Ml, Gimbrone Jr MA, Libby P. Inducible expression of vascular cell adhesion molecule-1 by vascular smooth muscle cells in vitro and within rabbit atheroma. Am J Pathol. 1993;143:1551-9.

9. Gu L, Okada Y, Clinton SK, et al. Absence of monocyte chemoattractant protein-1 reduces atherosclerosis in low density lipoprotein receptordeficient mice. Mol Cell. 1998:2:275-81.

10. Boring L, Gosling J, Cleary M, Charo IF. Decreased lesion formation in CCR2-/mice reveals a role for chemokines in the initiation of atherosclerosis. Nature. 1998;394:894-7.

11. Libby P, Ridker PM. Inflammation and atherosclerosis: role of C-reactive protein in risk assessment. Am J Med. 2004;116(Suppl 6A):9S-16.

12. Ridker PM, Danielson E, Fonseca FA, et al. Rosuvastatin to prevent vascular events in men and women with elevated C-reactive protein. N Engl J Med. 2008:359:2195-207.

13. Ridker PM, Hennekens CH, Buring JE, Rifai N. C-reactive protein and other markers of inflammation in the prediction of cardiovascular disease in women. N Engl J Med. 2000:342:836-43.

14. Lemieux I, Pascot A, Prud'homme D, et al. Elevated C-reactive protein: another component of the atherothrombotic profile of abdominal obesity. Arterioscler Thromb Vasc Biol. 2001;21:961-7.
15. Saito M, Ishimitsu T, Minami J, Ono H, Ohrui M, Matsuoka H. Relations of plasma high-sensitivity C-reactive protein to traditional cardiovascular risk factors. Atherosclerosis. 2003;167:73-9

16. Ridker PM, Rifai N, Clearfield M, et al. Measurement of C-reactive protein for the targeting of statin therapy in the primary prevention of acute coronary events. N Engl J Med. 2001;344:1959-65.

17. Ridker PM, Silvertown JD. Inflammation, C-reactive protein, and atherothrombosis. J Periodontol. 2008:79:1544-51.

18. Gisondi P, Fantin F, Del Giglio M, et al. Chronic plaque psoriasis is associated with increased arterial stiffness. Dermatology. 2009:218:110-3.

19. Prodanovich S, Kirsner RS, Kravetz JD, Ma F, Martinez L, Federman DG. Association of psoriasis with coronary artery, cerebrovascular, and peripheral vascular diseases and mortality. Arch Dermatol. 2009;145:700-3.

20. Kaye JA, Li L, Jick SS. Incidence of risk factors for myocardial infarction and other vascular diseases in patients with psoriasis. Br J Dermatol. 2008;159:895-902.

21. Yiu KH, Yeung CK, Zhao CT, Chan JC, Siu CW, Tam S, et al. Prevalence and extent of subclinical atherosclerosis in patients with psoriasis. J Intern Med. 2013:273(3):273-82. Epub 2012 Dec 28.

22. Libby $P$. Role of inflammation in atherosclerosis associated with rheumatoid arthritis. Am J Med. 2008:121:S21-31.

23. Sarzi-Puttini P, Atzeni $F$, Gerli R, et al. Cardiac involvement in systemic rheumatic diseases: An update. Autoimmun Rev. 2010;9:849-52.

24. Rho YH, Solus J, Raggi P, et al. Macrophage activation and coronary atherosclerosis in systemic lupus erythematosus and rheumatoid arthritis. Arthritis Care Res. 2011;63:535-41.

25. Garcia-Bermudez M, Lopez-Mejias R, Gonzalez-Juanatey C, et al. Analysis of the Interferon Gamma (rs2430561, +874 T/A) Functional Gene Variant in Relation to the Presence of Cardiovascular Events in Rheumatoid Arthritis. PLoS One. 2012;7, e47166.

26. Deo SS, Chogle AR, Mistry KJ, Shetty RR, Nadkar UL. Increased prevalence of subclinical atherosclerosis in rheumatoid arthritis patients of Indian descent. Expn Clin Cardiol. 2012;17:20-5

27. Packard RR, Lichtman AH, Libby P. Innate and adaptive immunity in atherosclerosis. Semin Immunopathol. 2009;31:5-22.

28. Srivastava RAK, Dalal R, Lobo A, Parikh S, Sharma S. A Novel Anti-inflammatory Natural Product and its Active Ingredient, 7-Hydroxy Frullanolide Inhibits Expression of VCAM1 and ICAM1, and Slows Progression of Athersoclerosis. Boston: International Atherosclerosis Society Meeting; 2009

29. Fonseca LC, Dadarkar SS, Lobo AS, et al. 7-hydroxyfrullanolide, a sesquiterpene lactone, inhibits pro-inflammatory cytokine production from immune cells and is orally efficacious in animal models of inflammation. Eur J Pharmacol. 2010:644:220-9.

30. Srivastava RA, Jahagirdar R, Azhar S, Sharma S, Bisgaier CL. Peroxisome proliferator-activated receptor-alpha selective ligand reduces adiposity, improves insulin sensitivity and inhibits atherosclerosis in LDL receptor-deficient mice. Mol Cell Biochem. 2006:285:35-50.

31. Srivastava RA, He S. Anti-hyperlipidemic and insulin sensitizing activities of fenofibrate reduces aortic lipid deposition in hyperlipidemic Golden Syrian hamster. Mol Cell Biochem. 2010;345:197-206.

32. Livak KJ, Schmittgen TD. Analysis of relative gene expression data using real-time quantitative PCR and the 2(-Delta Delta C(T)) Method. Methods. 2001;25:402-8

33. Srivastava RA. Evaluation of anti-atherosclerotic activities of PPAR-alpha, PPAR-gamma, and LXR agonists in hyperlipidemic atherosclerosissusceptible F(1)B hamsters. Atherosclerosis. 2011;214:86-93.

34. Paszty C, Maeda N, Verstuyft J, Rubin EM. Apolipoprotein Al transgene corrects apolipoprotein E deficiency-induced atherosclerosis in mice. J Clin Invest. 1994;94:899-903.

35. Reddick RL, Zhang SH, Maeda N. Atherosclerosis in mice lacking apo E. Evaluation of lesional development and progression. Arterioscler Thromb. 1994;14:141-7.

36. Baker RG, Hayden MS, Ghosh S. NF-kappaB, inflammation, and metabolic disease. Cell Metab. 2011:13:11-22.

37. Binion DG, Heidemann J, Li MS, Nelson VM, Otterson MF, Rafiee P. Vascula cell adhesion molecule-1 expression in human intestinal microvascular endothelial cells is regulated by PI 3-kinase/Akt/MAPK/NF-kappaB: inhibitory role of curcumin. Am J Physiol Gastrointest Liver Physiol. 2009;297:G259-68

38. Roman-Blas JA, Jimenez SA. Targeting NF-kappaB: a promising molecular therapy in inflammatory arthritis. Int Rev Immunol. 2008;27:351-74. 
39. Butt C, Sun S, Peddle L, et al. Association of nuclear factor-kappaB in psoriatic arthritis. J Rheumatol. 2005;32:1742-4.

40. Steffan NM, Bren GD, Frantz B, Tocci MJ, O'Neill EA, Paya CV. Regulation of IkB alpha phosphorylation by PKC-and $\mathrm{Ca}(2+)$-dependent signal transduction pathways. J Immunol. 1995;155:4685-91.

41. Inoguchi T, Li P, Umeda F, et al. High glucose level and free fatty acid stimulate reactive oxygen species production through protein kinase C-dependent activation of $\mathrm{NAD}(\mathrm{P}) \mathrm{H}$ oxidase in cultured vascular cells. Diabetes. 2000;49:1939-45.

42. Charles P, Elliott MJ, Davis D, et al. Regulation of cytokines, cytokine inhibitors, and acute-phase proteins following anti-TNF-alpha therapy in rheumatoid arthritis. J Immunol. 1999;163:1521-8.

43. Ohman MK, Wright AP, Wickenheiser KJ, Luo W, Russo HM, Eitzman DT. Monocyte chemoattractant protein-1 deficiency protects against visceral fat-induced atherosclerosis. Arterioscler Thromb Vasc Biol. 2010;30:1151-8.

44. Ross R. Atherosclerosis-an inflammatory disease. N Engl J Med. 1999;340:115-26.

45. Hehner SP, Heinrich M, Bork PM, et al. Sesquiterpene lactones specifically inhibit activation of NF-kappa B by preventing the degradation of I kappa B-alpha and I kappa B-beta. J Biol Chem. 1998;273:1288-97.

46. Madan B, Prasad AK, Parmar VS, Ghosh B. 1,4-dihydroxyxanthone modulates the adhesive property of endothelial cells by inhibiting intercellular adhesion molecule-1 (ICAM-1), vascular cell adhesion molecule-1 (VCAM-1) and E-selectin. Bioorg Med Chem. 2004;12:1431-7.

47. Sakai A. Diclofenac inhibits endothelial cell adhesion molecule expression induced with lipopolysaccharide. Life Sci. 1996;58:2377-87.

48. Liu SF, Ye X, Malik AB. Inhibition of NF-kappaB activation by pyrrolidine dithiocarbamate prevents In vivo expression of proinflammatory genes. Circulation. 1999;100:1330-7.

49. Nandate K, Ogata M, Tamura H, Kawasaki T, Sata T, Shigematsu A. $\mathrm{N}$-acetyl-cysteine attenuates endotoxin-induced adhesion molecule expression in human whole blood. Anesth Analg. 2005;100:1453-7. Table of contents.

50. Auld CA, Hopkins RG, Fernandes KM, Morrison RF. Novel effect of helenalin on Akt signaling and Skp2 expression in 3 T3-L1 preadipocytes. Biochem Biophys Res Commun. 2006;346:314-20.

51. Garcia-Pineres AJ, Lindenmeyer MT, Merfort I. Role of cysteine residues of p65/NF-kappaB on the inhibition by the sesquiterpene lactone parthenolide and N-ethyl maleimide, and on its transactivating potential. Life Sci. 2004;75:841-56

52. Ichikawa H, Nair MS, Takada Y, et al. Isodeoxyelephantopin, a nove sesquiterpene lactone, potentiates apoptosis, inhibits invasion, and abolishes osteoclastogenesis through suppression of nuclear factor-kappaB (nf-kappaB) activation and nf-kappaB-regulated gene expression. Clin Cancer Res. 2006;12:5910-8.

53. Fitzpatrick LR, Wang J, Le T. Caffeic acid phenethyl ester, an inhibitor of nuclear factor-kappaB, attenuates bacterial peptidoglycan polysaccharideinduced colitis in rats. J Pharmacol Exp Ther. 2001;299:915-20.

54. Watanabe M, Dewan MZ, Okamura T, et al. A novel NF-kappaB inhibitor DHMEQ selectively targets constitutive NF-kappaB activity and induces apoptosis of multiple myeloma cells in vitro and in vivo. Int J Cancer. 2005;114:32-8

55. Zhu YP, Shen T, Lin YJ, Chen BD, Ruan Y, Cao Y, et al. Astragalus polysaccharides suppress ICAM-1 and VCAM-1 expression in TNF-a-treated human vascular endothelial cells by blocking NF-kB activation. Acta Pharmacol Sin. 2013;34(8):1036-42. 2013.46 Epub 2013 Jun 3.

56. Ying Z, Kherada N, Farrar B, et al. Lipoic acid effects on established atherosclerosis. Life Sci. 2010;86:95-102.

57. Ying Z, Kherada N, Kampfrath T, et al. A modified sesamol derivative inhibits progression of atherosclerosis. Arterioscler Thromb Vasc Biol. 2011;31:536-42.

58. Chen H, Yang J, Zhang Q, Chen LH, Wang Q. Corosolic acid ameliorates atherosclerosis in apolipoprotein E-deficient mice by regulating the nuclear factor-kappaB signaling pathway and inhibiting monocyte chemoattractant protein-1 expression. Circ J. 2012;76:995-1003.

59. Gonzalez-Gay MA, Vazquez-Rodriguez TR, Gonzalez-Juanatey C, Llorca J. Subclinical atherosclerosis in patients with psoriatic arthritis. J Rheumatol. 2008;35:2070-1. author reply 2071.

60. Gonzalez-Gay MA, Gonzalez-Vela C, Gonzalez-Juanatey C. Psoriasis: a skin disease associated with increased cardiovascular risk. Actas Dermosifiliogr. 2012;103:595-8.
61. Balci DD, Balci A, Karazincir S, et al. Increased carotid artery intima-media thickness and impaired endothelial function in psoriasis. J Eur Acad Dermatol Venereol. 2009;23:1-6

62. Jamnitski A, Symmons D, Peters MJ, Sattar N, Mclnnes I, Nurmohamed MT Cardiovascular comorbidities in patients with psoriatic arthritis: a systematic review. Ann Rheum Dis. 2013;72(2):211-6. Epub 2012 Apr 24.

63. Gandhi S, Narula N, Marshall JK, Farkouh M. Are patients with inflammatory bowel disease at increased risk of coronary artery disease? Am J Med. 2012;125:956-62

64. Han C, Robinson Jr DW, Hackett MV, Paramore LC, Fraeman KH, Bala MV. Cardiovascular disease and risk factors in patients with rheumatoid arthritis, psoriatic arthritis, and ankylosing spondylitis. J Rheumatol. 2006;33:2167-72

65. Giles JT, Szklo M, Post W, et al. Coronary arterial calcification in rheumatoid arthritis: comparison with the Multi-Ethnic Study of Atherosclerosis. Arthritis Res Ther. 2009;11:R36.

66. Di Micco P, Ferrazzi P, Libre L, et al. Intima-media thickness evolution after treatment with infliximab in patients with rheumatoid arthritis. Int J Gen Med. 2009:2:141-4

67. Cavagna L, Boffini N, Cagnotto G, Inverardi F, Grosso V, Caporali R. Atherosclerosis and rheumatoid arthritis: more than a simple association. Mediators Inflamm. 2012;2012:147354.

68. Libby $\mathrm{P}$, Okamoto $Y$, Rocha VZ, Folco E. Inflammation in atherosclerosis: transition from theory to practice. Circ J. 2010;74:213-20.

69. Nusair MB, Rajpurohit N, Alpert MA. Chronic Inflammation and Coronary Atherosclerosis in Patients with End-Stage Renal Disease. Cardiorenal Med 2012;2:117-24.

70. Imanishi T, Akasaka T. Novel strategies to target inflammatory processes in atherosclerosis. Curr Pharm Des. 2013;19(9):1616-25.

71. Cuaz-Perolin C, Billiet L, Bauge E, et al. Antiinflammatory and antiatherogenic effects of the NF-kappaB inhibitor acetyl-11-keto-beta-boswellic acid in LPS-challenged ApoE-/- mice. Arterioscler Thromb Vasc Biol. 2008;28:272-7.

72. Bursill CA, Castro ML, Beattie DT, et al. High-density lipoproteins suppress chemokines and chemokine receptors in vitro and in vivo. Arterioscler Thromb Vasc Biol. 2010;30:1773-8

73. Srivastava RA, Srivastava N. High density lipoprotein, apolipoprotein A-I, and coronary artery disease. Mol Cell Biochem. 2000;209:131-44.

74. Gonen A, Harats D, Rabinkov A, et al. The antiatherogenic effect of allicin: possible mode of action. Pathobiology. 2005;72:325-34.

75. Auclair S, Milenkovic D, Besson C, et al. Catechin reduces atherosclerotic lesion development in apo E-deficient mice: a transcriptomic study. Atherosclerosis. 2009;204:e21-7.

76. Guri AJ, Misyak SA, Hontecillas R, et al. Abscisic acid ameliorates atherosclerosis by suppressing macrophage and CD4+ T cell recruitment into the aortic wall. J Nutr Biochem. 2010;21:1178-85.

77. Eilertsen KE, Maehre HK, Jensen IJ, et al. A wax ester and astaxanthin-rich extract from the marine copepod Calanus finmarchicus attenuates atherogenesis in female apolipoprotein E-deficient mice. J Nutr. 2012:142:508-12.

78. Gallaher CM, Gallaher DD. Dried plums (prunes) reduce atherosclerosis lesion area in apolipoprotein E-deficient mice. Br J Nutr. 2009;101:233-9.

79. Hishikawa K, Nakaki T, Fujita T. Oral flavonoid supplementation attenuates atherosclerosis development in apolipoprotein E-deficient mice. Arterioscler Thromb Vasc Biol. 2005;25:442-6.

80. Lopez-Franco O, Hernandez-Vargas P, Ortiz-Munoz G, et al. Parthenolide modulates the NF-kappaB-mediated inflammatory responses in experimental atherosclerosis. Arterioscler Thromb Vasc Biol. 2006;26:1864-70.

81. Mangathayaru K, Kuruvilla S, Balakrishna K, Venkhatesh J. Modulatory effect of Inula racemosa Hook. f. (Asteraceae) on experimental atherosclerosis in guinea-pigs. J Pharm Pharmacol. 2009;61:1111-8. 